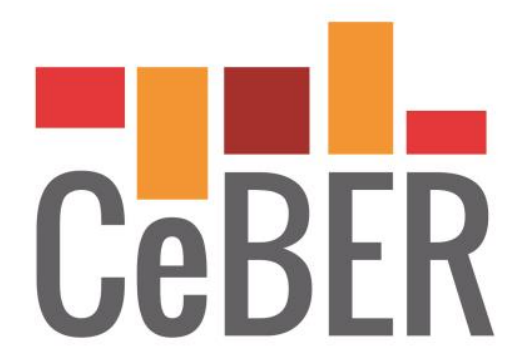

CENTRE FOR BUSINESS AND ECONOMICS RESEARCH UNIVERSITY OF COIMBRA

\title{
Endogenous Growth and Entropy
}

\author{
TIAGO NEVES SEQUEIRA \\ Univ. Beira Interior and CEFAGE-UBI
}

PEDRO MAZEDA GIL

University of Porto, Faculty of Economics, and CEF.UP

ÓSCAR AFONSO

University of Porto, Faculty of Economics, CEF.UP, and CEFAGE-UBI

\section{CeBER Working Papers}

No. 5 


\title{
Endogenous Growth and Entropy*
}

\author{
Tiago Neves Sequeira ${ }^{\dagger}$ \\ Univ. Beira Interior and CEFAGE-UBI \\ Pedro Mazeda Gil ${ }^{\ddagger}$ \\ University of Porto, Faculty of Economics, and CEF.UP \\ Óscar Afonso ${ }^{\S}$ \\ University of Porto, Faculty of Economics, and CEF.UP, and CEFAGE-UBI
}

\begin{abstract}
This paper offers novel insights regarding the role of complexity in both the transitional and the long-run dynamics of the economy. We devise an endogenous growth model using the concept of entropy as a state-dependent complexity effect. This allows us to gradually diminish scale effects as the economy develops along the transitional dynamics, which conciliates evidence on the existence of scale effects in history with evidence of no or reduced scale effects in today's economies. We show that empirical evidence supports entropy as a "first principle" operator of the complexity effect. The model features endogenous growth, with null or small (positive or negative) scale effects, or stagnation, in the long run. These different long-run possibilities have also policy implications. Then, we show that the model can replicate well the take-off after the industrial revolution and the productivity slowdown in the second half of the $\mathrm{XX}^{t h}$ century. Future scenarios based on in-sample calibration are discussed, and may help to explain (part of) the growth crises affecting the current generation.
\end{abstract}

Keywords: endogenous economic growth, complexity effects, entropy.

JEL Classification: O10, O30, O40, E22

\footnotetext{
*Previous versions of this paper circulated under the title "Growth without scale effects due to entropy". We thank the helpful comments on earlier versions from Jaime Alonso, Margarida Duarte, Yuichi Furukawa, Reyer Gerlagh, Jakub Growiek, Harry Huizinga, Pietro Peretto, Xavier Raurich, John Seater, Sjak Smulders, and participants in the $10^{t h}$ Portuguese Economic Journal Conference (Univ. Coimbra, July 2016), DEGIT XXI Conference (Univ. Nottingham, UK, Sept. 2016), V LubraMacro (Portuguese-Brazilian Meeting of Macroeconomics, Sept. 2016), Workshop on Economic Growth, Innovation and Finance (SKEMA Business School, France, June 2017), Finance and Economic Growth in the Aftermath of the Crisis (Univ. Milan, Sept. 2017), EEA-ESEM (Lisbon, Aug. 2017) and seminars in Univ. Porto, Minho, Vigo, Barcelona and Tilburg. We thank Jakob Madsen for supplying the historical series for R\&D intensity. All remaining errors are ours alone. This research has been financed by the European Regional Development Fund through COMPETE 2020 Programa Operacional Competitividade e Internacionalizao (POCI) and by Portuguese public funds through FCT (Fundação para a Ciência e a Tecnologia) in the framework of the project POCI01-0145-FEDER-007659 (CEFAGE) and POCI-01-0145-FEDER-006890 (CEF.UP)

†Departamento de Gestão e Economia and CEFAGE-UBI - Center for Advanced Studies in Management and Economics. Universidade da Beira Interior. Avenida Marques d'Avila e Bolama, 6200-001 Covilhã, Portugal. Corresponding author. e-mail: sequeira@ubi.pt.

$\ddagger$ University of Porto, Faculty of Economics, and CEF.UP - Center for Economics and Finance at University of Porto.

$\S$ University of Porto, Faculty of Economics, and CEF.UP - Center for Economics and Finance at University of Porto, and CEFAGE-UBI.
} 


\section{Introduction}

The core of the innovation-based endogenous growth theory is the technology for the production of knowledge. In fact, underlying the discussions in the field are the asymptotic properties of a function of the type $A_{t+1}=f\left(A_{t}, L_{t}^{A}\right)$, where $A$ is the stock of ideas or knowledge, $L^{A}$ summarizes the physical factors affecting the production of knowledge and $t$ is the time index. In order to obtain endogenous growth, the derivative of $f\left(A_{t}, L_{t}^{A}\right)$ with respect to $A_{t}$ must be constant and larger than unity in the long run (i.e., asymptotically). That is, endogenous growth requires that an increase in the stock of knowledge, even when this stock is already infinitely large, still leads to some new ideas (e.g., Peretto and Smulders, 2002; Dalgaard and Kreiner, 2003).

On the other hand, in spite of the modern evidence against (strong) scale effects on economic growth, ${ }^{1}$ historical evidence indicates that the level of population and connections between civilizations determined economic growth rates (e.g., Sokoloff, 1988; Kremer, 1993). Until now, the apparent contradiction between the today's evidence and the historical evidence on the existence of scale effects has not been completely incorporated into the economic growth literature, although some attempts have been made. Dinopoulos and Thompson (1998) have briefly mentioned this dichotomy and shown that it can be approached through the analysis of transitional dynamics (see also e.g. Jones, 2002 and Strulik et al., 2013). Peretto and Smulders (2002) also look at the asymptotic properties of the knowledge function in a model in which the scale effects always vanish asymptotically. In turn, Alesina et al. (2005) showed that not only is there historical evidence of significant scale effects, but also there may be some scale effects nowadays if both size and openness are taken as joint determinants of economic growth.

Our paper addresses the interplay between endogenous growth and scale effects by considering an 'operator' that introduces concavity with respect to knowledge in the knowledge production function, but which is compatible with the asymptotic properties that allow for endogenous growth in the long run. The 'operator' allows for both transitional dynamics in the stock of knowledge (independently of the consideration of decreasing marginal returns to physical capital and of time-varying growth rates of physical inputs to knowledge production) and the dilution of strong scale effects in the long run. Thereby, we conciliate the existence of scale effects long ago in history with evidence of no or reduced scale effects in today's economies. Transitional dynamics may be non-monotonic (inverted-U shaped), also by the sole action of the 'operator', which contrasts with the previous literature and addresses the non-linear behavior also observed in the data on growth rates. However, the 'operator' is also flexible enough to account for some - negative or positive - scale effects even in the long run, which may be crucial to generate contrasting scenarios for the longrun dynamics. We do not endow this 'operator' with arbitrary properties, but instead we borrow them from 'first principles' through the concept of entropy as a measure of disorder, redundancy or diversity (as developed in Thermodynamics, Information Theory, and Biology, respectively). We take advantage of the proximity between the entropy concept and the difficulty or complexity associated with the quantity of knowledge in Economics to build our 'operator' as a complexity index, which is time-varying solely by means of this state (knowledge) dependence. Thus, this index works, we think, as a 'summary statistics' of the relevant economics pertaining to this issue with a minimum loss of information.

Moreover, our model inherits the piecewise dynamical structure that arises in the innovationdriven endogenous growth models. This structure reflects that, if the expected profit of R\&D

\footnotetext{
${ }^{1}$ Growth rates have not always accelerated globally as population increased and bigger countries do not grow systematically at higher rates than smaller ones.
} 
is not sufficiently large in order to exceed the respective cost, then there is a corner solution at which no R\&D occurs. Our paper takes this feature explicitly into account in line with, e.g., Strulik et al. (2013) and Peretto (2015), to study the switch from stagnation to innovation-driven growth and, also a possibility in our model, from growth to stagnation again - as a result of the interaction, over time, between (positive or negative) scale effects commanded by the complexity index and knowledge accumulation and population growth.

We show that the transitional dynamics in the model can match well the historical evolution of TFP and per capita GDP in the developed world after the Industrial Revolution. With different parameterizations of the complexity index based on entropy, the model is able to replicate an almost ever increasing growth rate from the eve of the Industrial Revolution, with decelerations of growth during the World War II and accelerations during the "roaring twenties" or during the recovery from the war period during the 1960s. The model is also capable of predicting the productivity slowdown after the 1960s.

Given the flexibility introduced by the complexity index as regards the remaining scale effects in the long run (null or small positive or negative), we are able to predict distinct future scenarios: there will be positive economic growth in the long run - although (possibly) lower than over the $\mathrm{XX}^{\text {th }}$ century - despite (eventual) population stagnation; or economic stagnation will occur due to population growth (although the latter will eventually stagnate in the long run).

Policy implications arise from the model. In particular R\&D subsidies can trigger an exogenous impulse to drive the economy out of the stagnation regime. Additionally, the introduction of R\&D subsidies can also be responsible for a delay in stagnation, both if it occurs due to population growth or if it would occur due to an ever rising complexity effect.

Our paper is particularly close to Peretto and Smulders (2002) and Dalgaard and Kreiner (2003). The latter take a general point on the relevance of the asymptotic properties of the knowledge production function that allow for endogenous growth in the long run. They show analytically that the knowledge production function may exhibit decreasing or increasing returns over time, but the crucial condition for endogenous growth is that the marginal product of knowledge in that production function converges towards a positive constant in the long run. However, they analyze a CES specification for the knowledge production function as an ad hoc example and do not develop a full growth model. Peretto and Smulders (2002) study an endogenous growth model of vertical and horizontal R\&D that exhibits scale effects (which may be positive or negative) over time but that vanish asymptotically. They model the incremental process of increasing complexity in an expanding economy as follows: vertical R\&D expands the public knowledge stock and gives rise to spillovers, while horizontal R\&D leads to higher specialization in R\&D activities and an increased technological distance between firms, thereby diluting spillovers and causing the scale effects to vanish asymptotically. Analytically, Peretto and Smulders consider two state variables, the average knowledge stock and the number of firms, and derive their results by considering a linear relationship between spillovers and the average knowledge stock and a non-linear, but bounded relationship between spillovers and the number of firms. The asymptotic result arises from the former relationship. In turn, our paper features a similar asymptotic behavior, but which is commanded by the dynamics of one state variable, the stock of knowledge or, more specifically, the number of varieties of technological goods in the economy. This variable appears as the single argument of the 'operator' used as a complexity index and that drives our results over time. We take advantage of our more parsimonious analytical structure to take the knowledge production function to the data and perform quantitative analysis through calibration. At the same time, as explained earlier, the properties of the 
complexity index allow for non-monotonic transitional dynamics and also imply that different scenarios may emerge as regards the amount of (small) scale effects remaining in the log run - and, hence, the sustainable dynamics of the economy (growth versus stagnation).

Along a different line, Strulik et al. (2013) lay out a model that integrates knowledge accumulation through learning-by-doing and $R \& D$ activities into a framework with endogenous fertility and human capital accumulation through schooling. Learning-by-doing depends positively on the scale of the economy measured by population size but features decreasing returns, so that, asymptotically, it plays no role in the growth of the stock of knowledge. R\&D operates under the assumption of decreasing returns to the existing stock of knowledge, so that R\&D becomes more difficult over time. Together, these two features imply that scale effects on growth vanish as the economy approaches steady-state growth. At the same time, this setup implies that the steady-state growth rate is solely driven by the rate of human capital accumulation (in turn driven by the productivity of schooling), whereas the population growth rate (driven by endogenous fertility) only has transitional dynamics effects. In a calibration exercise that analyses the transition towards steady-state growth, it is shown that the model predicts an inverted-U behavior for TFP growth, with an acceleration over the $20^{\text {th }}$ century being followed by a slowdown from the year 2000 onwards. The fertility rate and population growth are crucial for this behavior, as they are still high when $R \& D$ activities are gathering speed (at the beginning of the 20th century) and scale effects are still present, but they then start a steep fall as human capital accumulation takes up. Overall, this movement induces a gradual reduction of the TFP growth rate towards its steady-state value. ${ }^{2}$ Our paper explores a complementary mechanism to that in Strulik et al. (2013). Our model generates a non-monotonic transition of the TFP growth rate commanded by the complexity index dynamics irrespective of an (eventual) deceleration of the population or fall in fertility. ${ }^{3}$ At the same time, as already noted, our model allows for the discussion of contrasting future scenarios for the growth of modern economies because scale effects do not necessarily strictly vanish asymptotically and there is the chance some small (negative or positive) scale effects persist even in the long run.

This paper is organized as follows. Section 2 presents the theoretical foundation of the entropy function to model a time-varying state-dependent complexity effect. Section 3 presents the knowledge production function and empirical evidence that allows us to infer the complexity effect from the time-series data and calibrate the complexity index. Section 4 presents the model, its steady-state and transitional dynamics. Section 5 presents the quantitative study of the model through calibration and compares the results with historical data. In this Section, we also extend the quantitative exercises to the future, highlighting possible scenarios for the long-run growth. Finally, Section 6 draws conclusions.

\section{Theoretical Insight}

Although the concept of entropy originated in Thermodynamics - commonly understood as a measure of molecular disorder within a macroscopic system - and its statistical definition was developed in Statistical Mechanics, it has been adapted and extended by other fields

\footnotetext{
${ }^{2}$ The underlying mechanism that generates this result is similar to the one in the baseline growth model with R\&D featuring decreasing returns to the stock of knowledge. Ha and Howitt (2007) show how the baseline model generates an inverted-U transition for TFP growth if the growth rate of the R\&D input is falling over time and the TFP growth rate is initially below its steady-state value.

${ }^{3}$ In particular, our model is able to replicate relevant instances of the data, noticeably the TFP slowdown after the 1960s, whereas Strulik et al. (2013) model places the slowdown about two generations later.
} 
of study, including Information Theory, Biology, and Economics. ${ }^{4}$ As such, several indices have been created to measure entropy, although with different interpretations: examples are the Boltzmann-Gibbs entropy index and the Tsallis entropy index (a generalization of Boltzmann-Gibbs) as a measure of uncertainty in Statistical Mechanics (e.g., Tsallis, 1988); the Shannon index, as a measure of redundancy in Information Theory (Shannon, 1948); the Patil and Taillie index (equivalent to the Tsallis index), as a measure of diversity in Biology (Patil and Taillie, 1982); and the Atkinson index (a transformation of a generalized entropy index), as a measure of income inequality in Economics (Atkinson, 1970). As time goes on, a simple system may get more and more complicated. As this happens, there is an increasing difficulty to deal with all the pieces of the system, to measure it and to account for its changes. Entropy accounts for and measures this rise in complexity as time passes by.

In particular, we emphasize the analogy of the entropy concept in Information Theory and Biology with the difficulty or complexity associated with the quantity of knowledge that is accumulated in an economy. In the context of an endogenous growth model of horizontal $\mathrm{R} \& \mathrm{D}$, complexity rises as the economy develops and increases the number of varieties of capital (or technological) goods. Indeed, complexity may be understood as a process. Economies at earlier stages of development are characterized by relatively simple production methods and a limited availability of specialized inputs, in a context in which the diversity of human activities and of produced goods and services is low (Ciccone and Matsuyama, 1996). Complexity rises as the economy develops and increases the diversity (and redundancy) of its activities. In developed economies production industries make extensive use of highly specialized inputs and have access to a wide variety of producer services, such as equipment repair and maintenance, transportation and communication services, engineering and legal supports, accounting, advertising, and financial services (see Ciccone and Matsuyama, 1996, and the extensive references therein).

A widely used family of entropy indices based on the contributions by Tsallis and by Patil and Taillie is usually written in the form

$$
S_{q}=\left\{\begin{array}{ll}
\frac{1-\sum_{i=1}^{W} p_{i}^{q}}{q-1} & , q \neq 1 \\
-\sum_{i=1}^{W} p_{i} \ln p_{i} & , q=1
\end{array},\right.
$$

where $p_{i}$ is the probability that a system is in the $i^{t h}$ state, $W$ is the number of states, and $q$ is a non-negative parameter. $S_{q}$ represents a parametric family of indices of degree $q-1$, with some limiting values representing well-known indices that measure biological diversity or informational redundancy. For instance, with $q=1$, one recovers the Shannon entropy index as a special case of the Tsallis index and of the Patil and Taillie indices. In general, each specific application of the index $S_{q}$ requires the determination of a particular value of $q .^{5}$

If the distribution is uniform, such that, e.g., all the messages in the message space or

\footnotetext{
${ }^{4}$ In statistical thermodynamics, entropy is a measure of the number of microscopic configurations that correspond to a thermodynamic system in a state specified by certain macroscopic variables. This is often interpreted as the degree of disorder or lack of predictability of a system. For example, a gas in a container with known volume, pressure, and temperature could have an enormous number of possible configurations of the individual gas molecules, and which configuration the gas is actually in may be regarded as random. Entropy is maximum when the individual gas molecules are equally spread throughout the container.

${ }^{5}$ To see more precisely the role played by $q$ in this framework, consider two probabilistically independent subsystems $X$ and $Z$ with, respectively, the number of states $W^{X}$ and $W^{Z}$. Equation (1) implies $S_{q}^{X \cup Z}=$ $S_{q}^{X}+S_{q}^{Z}+(1-q) S_{q}^{X} S_{q}^{Z}$. The case of $q=1(q \neq 1)$ amounts to "additive" ("non-additive") entropy (Caruso and Tsallis, 2008). The above also implies that the system is "extensive"when $q=1$, with the property that entropy approaches proportionality with the number of elements of the system when the number is large. The system is called "nonextensive" otherwise, where $q<1(q>1)$ corresponds to "superextensivity" ("subextensivity") (Tsekouras and Tsallis, 2005).
} 


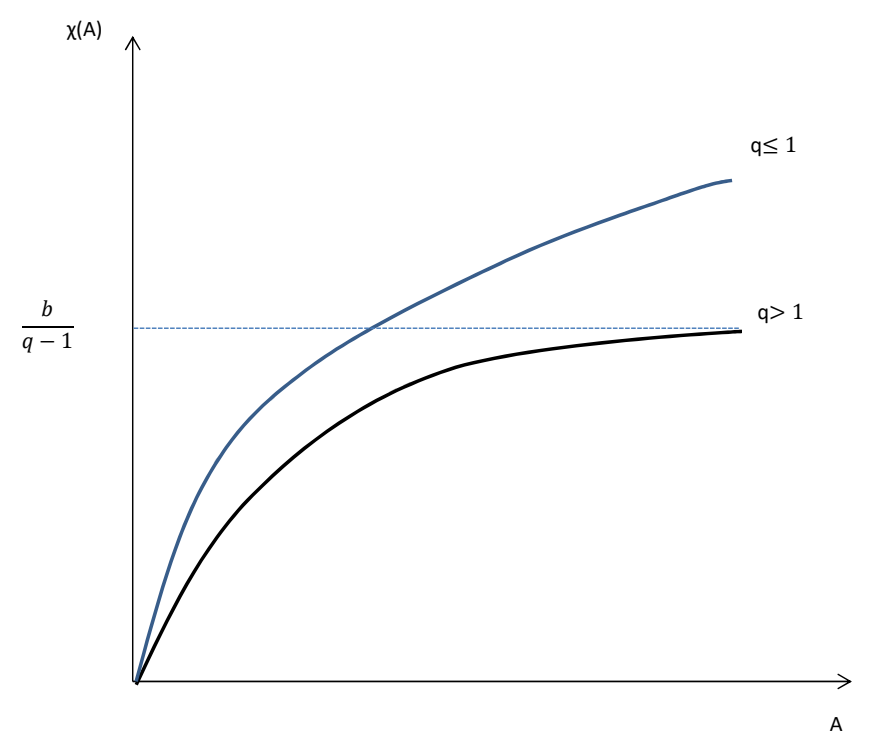

Figure 1: $\chi(A)$ function for different intervals of $q$

the biological varieties (species) in the variety space are equiprobable, $p=1 / W$, the entropy is maximized and $S_{q}$ becomes

$$
S_{q}=\left\{\begin{array}{ll}
\frac{1-W^{1-q}}{q-1} & , q \neq 1 \\
\ln W & , q=1
\end{array},\right.
$$

The entropy indices may also be computed up to a constant of proportionality (which sometimes is known as the Boltzmann constant). Given the referred to analogy between the concepts of entropy and of complexity, we use the Tsallis-Patil-Taillie entropy index as a difficulty or complexity index associated with $A$, which stands for the stock of knowledge or, more specifically, the number of varieties of technological goods that are accumulated in an economy. Then, considering $p=1 / A$ and the referred to constant of proportionality, we obtain

$$
S_{q}\left(A_{t}\right)=\left\{\begin{array}{ll}
b \frac{1-A_{t}^{1-q}}{q-1} & , q \neq 1 \\
b \ln A_{t} & , q=1
\end{array},\right.
$$

with $b$ positive constant. Thus, $b$ can be regarded as a scale-shifter parameter (it shifts units of $A$ into units of the entropy index), whereas $q$ is an elasticity parameter that maps relative changes in $A$ into relative changes in the entropy index.

We will consider the complexity index, $\chi\left(A_{t}\right)$, as

$$
\chi\left(A_{t}\right)=\max \left\{0, S_{q}\left(A_{t}\right)\right\} .
$$

By using the measure of entropy given by the Tsallis-Patil-Taillie index, equation (4) shows that the complexity index $\chi\left(A_{t}\right)$ arises as a positive and concave function of the technological level $A_{t}$. Figure 1 shows a graphical representation of equation (4).

The following lemma shows that there is a specific set of values of parameter $q$ in equation (4) for which $\chi\left(A_{t}\right)$ converges to a constant. ${ }^{6}$

\footnotetext{
${ }^{6}$ As shown in the Lemma below, this result corresponds to $q>1$. In light of footnote 5 , this then means that convergence of $\chi\left(A_{t}\right)$ arises when the system is subextensive and is characterized by $S_{q}^{X \cup Z}<S_{q}^{X}+S_{q}^{Z}$.
} 
Lemma 1. With $q>1$, then $\chi\left(A_{t}\right)$ converges to $\frac{b}{q-1}$; thus for $b=q-1, \chi\left(A_{t}\right)$ converges to 1 as $A$ goes to infinity. With $q \leq 1$ then $\chi\left(A_{t}\right)$ goes to $+\infty$.

Proof. Calculate $\lim _{A \rightarrow+\infty} \chi\left(A_{t}\right)$ for $q>1$ and $q \leq 1$ in equation (3), respectively.

Thus, formally, we consider that complexity, though time-varying, is not a direct function of time, but is state dependent, where the state of the economy is given by the number of varieties of technological goods.

In the next Section we will show that this theoretical foundation for the complexity effect can reasonably match the empirical series, given the available data.

\section{Knowledge Production Function, Empirical Inference and Calibration}

In this section, we adapt our complexity index, based on the concept of entropy as a measure of redundancy or diversity, to a knowledge production function featuring complexity effects in R\&D, as put forward by the endogenous non-scale growth literature (e.g., Dinopoulos and Segerstrom, 1999; Barro and Sala-i-Martin, 2004). This literature captures the idea that the difficulty of introducing new products and replacing old ones is proportional to the market size, measured by the absolute level of output attributable to the product targeted by $R \& D$ and often linked with population size. The larger the market size, the larger the costs necessary to discover, develop and market the associated technology - e.g., costs pertaining to the construction of prototypes and samples, new assembly lines and training of workers, and generic coordination, organizational, marketing, and transportation costs. These complexity costs offset the positive effect of scale on the (expected) profits of the successful innovator. This way, scale variables like the level of the population tend not influence the steady-state growth rate because the probability of research success is also independent of those variables. ${ }^{7}$

In particular, our knowledge production function extends the ones in, e.g., Dinopoulos and Thompson (1999, 2000), Ha and Howitt (2007) and Ang and Madsen (2015), by considering an operator, the complexity index $\chi$, that introduces concavity with respect to knowledge, $A$, but which is compatible with the asymptotic properties that allow for endogenous growth in the long run, as explained below: ${ }^{8}$

$$
\begin{gathered}
\Delta A_{t+1}=\left(A_{t+1}-A_{t}\right)=\delta \cdot A_{t} \cdot \frac{1}{L_{t}} \cdot L_{t}^{1-\chi\left(A_{t}\right)} \cdot L_{t}^{A} \Leftrightarrow \\
\Leftrightarrow A_{t+1}=\delta \cdot A_{t} \cdot \frac{L_{t}^{A}}{L_{t}^{\chi\left(A_{t}\right)}}+A_{t} \equiv f\left(A_{t}, L_{t}^{A}, L_{t}\right),
\end{gathered}
$$

where $L_{t}^{A}$ is the aggregate amount of labor allocated to $\mathrm{R} \& \mathrm{D}$ activities, $L_{t}$ is a scale variable (measure of market dimension) proportional to the size of total labor force in the economy,

\footnotetext{
${ }^{7}$ Complexity costs are considered alternatively in the final good production such as in Bucci (2015) and Bucci et al. (2017). Some other articles consider production-complexity related benefits (i.e., as a growth enhancing feature) in the economy (e.g., Hidalgo and Hausman, 2009, and Afonso and Magalhães, 2017). These approaches should be clearly distinguished from that followed by the literature cited in the text.

${ }^{8}$ Later, in Section 5.1.2, we extend our analysis to a more general knowledge production function that allows for international knowledge spillovers and also flexible domestic spillovers. The latter allow one to account also for difficulty effects in innovation (capturing the notion that ideas that are easier to discover tend to be discovered first), impinging directly as a concavity of the knowledge production function in $A$ in line with e.g., Jones (1995) and Segerstrom (1998) (see also footnote 30 below).
} 
$\chi(A)$ is the time-varying state-dependent complexity index, which controls for the relationship between the scale of the economy and the (net) complexity costs on $R \& D$, and $\delta$ is the productivity in R\&D. By looking at the first row of (5), one can decompose the component of the knowledge production function that is external to R\&D firms as follows: $A_{t}$ denotes the knowledge spillovers, $1 / L_{t}$ captures the market-scale complexity costs (as considered by the literature cited above), and $L_{t}^{1-\chi(A)}$ captures the human spillovers. The latter arise because the productivity of the labor input in $R \& D$ firms benefits from the interaction with the overall human factor in the economy (as in, e.g., Lucas, 1988); but these benefits are curtailed as the complexity of the economy (controlled by $\chi(A)$ ) also increases, as this implies an increasing diversity of human activities and thus of the 'technological distance' between them (e.g., Peretto and Smulders, 2002). ${ }^{9}$ This specification allows us to nest existing specifications in the literature as special cases: if $\chi=0$, we recover the knowledge production function in Romer (1990) - no net complexity effects, full scale effects on growth; if $\chi=1$, we get the function in, e.g., Dinopoulos and Thompson $(1999,2000)$ - full net complexity effects, no scale effects on growth.

Lemma 2 summarizes the results regarding the asymptotic properties of the knowledge function with respect to $A$, and according to which the operator based on entropy implies either endogenous growth or stagnation.

Lemma 2. With $q>1$, then there is endogenous growth: (i) with positive scale effects if $b<q-1$; (ii) with no scale effects if $b=q-1$; (iii) with negative scale effects if $b>q-1$. With $q \leqslant 1$, technological growth vanishes asymptotically. All in all, the degree of scale effects decrease with technological progress.

Proof. Notice first that, under labor market equilibrium, $L_{t}^{A}$ and $L_{t}$ grow at the same rate in the long run. Use Lemma 1 and equation (5) to see that, with $q>1, \lim _{A \rightarrow+\infty} f_{A}>1$ or, equivalently, $\lim _{A \rightarrow+\infty}\left(\Delta A_{t+1} / A_{t}\right)>0$ - implying growth in the long run - and, with $q \leq 1, \lim _{A \rightarrow+\infty} f_{A}=1$ or, equivalently, $\lim _{A \rightarrow+\infty}\left(\Delta A_{t+1} / A_{t}\right)=0$ - implying stagnation in the long run. Both results arise independently of the existence of population growth, i.e., growth in $L_{t}^{A}$ and $L_{t}$. However, with $q>1$ and: (i) $b<q-1$, implying $\lim _{A \rightarrow+\infty}$ $\chi\left(A_{t}\right)<1$, there are positive scale effects on growth, since $\Delta A_{t+1} / A_{t}=\delta \cdot L_{t}^{A} / L_{t}^{\chi}\left(A_{t}\right)$ increases as term $L_{t}^{A} / L_{t}^{\chi\left(A_{t}\right)}$ increases due to population growth; (ii) $b=q-1$, implying $\lim _{A \rightarrow+\infty} \chi\left(A_{t}\right)=1$, there are no scale effects on growth, since term $L_{t}^{A} / L_{t}^{\chi\left(A_{t}\right)}$ becomes constant under population growth and hence $\Delta A_{t+1} / A_{t}$ is also constant; (iii) $b>q-1$, implying $\lim _{A \rightarrow+\infty} \chi\left(A_{t}\right)>1$, there are negative scale effects on growth since $\Delta A_{t+1} / A_{t}$ falls as term $L_{t}^{A} / L_{t}^{\chi\left(A_{t}\right)}$ decreases due to population growth.

We now wish, as a first step, to infer the complexity effect from the historical data and, as a second step, to calibrate the entropy function (the complexity index) to approximate the complexity effect computed in the first step.

Thus, in the first step, by applying logs to equation (5) and solving for $\chi$, we have the recursive equation:

$$
\chi=\frac{\ln \delta+\ln A_{t}+\ln L_{t}^{A}-\ln \left(\Delta A_{t+1}\right)}{\ln L_{t}} .
$$

To obtain estimates for $\chi$ over time, we consider the calibrated values of $\delta$ and the U.S. time series data for $A, L^{A}$ and $L$. We have used total labor force for $L$ between 1950 and 2000, from the Penn World Tables (PWT) 8.1. For the number of workers employed

\footnotetext{
${ }^{9}$ As explained in Section 1, these authors study a mechanism of increasing technological distance between firms to dilute knowledge spillovers and thus cause the scale effects to vanish asymptotically in the economy.
} 
in $\mathrm{R} \& \mathrm{D}, L^{A}$, we used the Number of Full-Time-Equivalent (FTE) R\&D scientists and engineers in R\&D-performing companies from the National Science Foundation. Finally in order to obtain $A_{t}$, we use a TFP index (with the 2005 level equalized to 1000) inferred from the (per capita) production function $y_{t}=\left(A_{t}\right)^{\sigma}\left(l_{t}^{Y}\right)^{1-\alpha} k_{t}^{\alpha}$, using output per worker for $y_{t}$ and physical capital per worker for $k_{t}$ (from the Penn World Tables 8.1), with parameters $\alpha=0.36$ (share of physical capital in GDP) and $\sigma$ (returns to knowledge, i.e., the measure of the social benefit from innovations) is 0.2 in line with the results presented by Coe et al. (2009: Table 4) for the G7 group of countries. ${ }^{10}$ Finally note that in the model workers are allocated either to the final-good production or to the R\&D labs, so we infer the ratio of workers in the production sector to total labor force $l_{t}^{Y}$ using the data for $L^{A}$ and $L$ already mentioned above. The parameter $\delta$ is adjusted such that we obtain a steady-state growth rate in the model of $1.87 \%{ }^{11}$ In order to present results for larger time span than the directly available data allowed us to, we extrapolated backwards the series until 1870 . In order to extrapolate the series for output per capita, physical capital per capita and employment we used the annual averaged growth rates from the decennial growth rates provided by the series in Baier et al. (2006) for output per worker, capital per worker and labor force. In order to extrapolate backwards the series for $L^{A}$ (employment in R\&D), we have used a contemporaneous relationship with R\&D expenditures (as a share of output) for the period between 1954 and 2000 and used then that series (from Ang and Madsen, 2015) to estimate our $L^{A}$ series. Alternatively to the use of TFP, we also used the U.S. patent stock from 1870 to 2000 (from the United States Patent Office) as a proxy of $A_{t} \cdot{ }^{12}$ The resulting series are plotted in Figure 2 in blue. In the Figure we plot three different time spans: $1870-2000 ; 1900-2000$ and 1950-2000 in order to account for possible structural change in the behaviour of $\chi$ throughout such a long historical period. We may note that the empirical series approach unity in the end of the period (2000), and this is a result one would expect, given that we are using data for a developed country. This also means that data suggests that the economy is behaving as an endogenous growth one with no (or small positive or negative) scale effects - recall Lemma 2.

As a second step, we compare those series with the theoretical ones that come from the insertion of the resulting series for $A_{t}$ in the complexity function (4). Using the obtained series for $\chi$ and $A_{t}$, we estimate $b$ and $q$ in equation (4) by GMM (Generalized Methods of Moments) such that we obtain the best possible fit between the theoretical and the empirical series (see also Table 1). Thus in the same Figure 2, we plot in red the theoretical adjustment to the empirical function inserting the estimated coefficients in equation (4) - We can observe that we obtain a very reasonable adjustment between the empirical series (for different time series available) and our theoretical formulation of the complexity effect. Estimated parameters (Table 1) indicate that several cases may be accomplished, in particular $b \lesseqgtr q-1$. Moreover absolute values of the estimations of $b$ and $q$ seem to

\footnotetext{
${ }^{10}$ The constant value for the share of physical capital on income is often regarded as a stylized fact (initially by Kaldor, 1961). Elsby et al. (2013) present evidence according to which capital share is around 0.36 between 1950 and 2000. Values for returns to knowledge are within the range of other empirical results reported by Hall et al. (2009) and Ugur et al. (2016).

${ }^{11}$ This is the average annual growth rate of GDP per worker in the United States between 1950 and 2000 , from the PWT 8.1.

${ }^{12}$ Following Ang and Madsen (2015), the initial patent stock is obtained by using the Solow model steady state value of $A_{0} /(\delta+g)$, where $A_{0}$ is initial patent granted, $\delta$ is the rate of depreciation (assumed to be $15 \%)$, and $g$ is the growth rate in patent issued over the period for which patent applications data are first available to 2000. We use a series for patent issued belonging to classifications 1 to 5 (chemical, computers and communications, drugs and medical, electrical and electronics, mechanical) in the NBER Classification (Marco et al., 2015). The objective was to include patents directly linked with innovations in high-advanced intermediate inputs (excluding some patents in low technology inputs - such as agriculture - and in final consumption goods - such as amusement devises). However, tests with the total issued and applications of patents did not significantly change our results.
} 
point to the case of endogenous growth with no (or small positive or negative) scale effects ( $q>1, b$ close to $q-1$; see again Lemma 2 ) and seem to reject the case of technological growth vanishing asymptotically $(q \leq 1)$. All the results are confirmed at $1 \%$ significance level. ${ }^{13,14}$ In Figure 2 we use the estimated values from Table 1.

Table 1: Estimation of the Complexity Function

\begin{tabular}{cccc|cccc}
\hline \hline & TFP & data & \multicolumn{3}{|c}{ Patent } & data \\
\hline \hline$\hat{b}$ & $\hat{q}$ & $S . E_{\cdot b}$ & $S . E_{._{q}}$ & $\hat{b}$ & $\hat{q}$ & $S . E_{\cdot b}$ & $S . E_{\cdot q}$ \\
\hline \multicolumn{5}{c}{ period: } \\
\hline 2.08 & 3.19 & 0.50 & 0.54 & 0.23 & 1.17 & 0.01 & 0.02 \\
\hline \multicolumn{5}{c}{ period: } \\
\hline 1.58 & 2.66 & 0.19 & 0.20 & 0.24 & 1.18 & 0.01 & 0.02 \\
\hline \multicolumn{5}{c}{ period: } \\
\hline 0.55 & 1.55 & 0.04 & 0.05 & 0.36 & 1.36 & 0.02 & 0.03 \\
\hline \hline
\end{tabular}

Notes: Calibrated values: $\alpha=0.36 ; \sigma=0.2 ; g_{y}=1.87 \%$. GMM non-linear estimation.

Instruments: R\&D expenditures (as a share of output) and time. All coefficients are significant at the $1 \%$ level (see also footnote 7 ). Standard-errors (S.E.) were computed using estimation of weighting matrix HAC (Bartlett kernel, Newey-West fixed bandwidth).

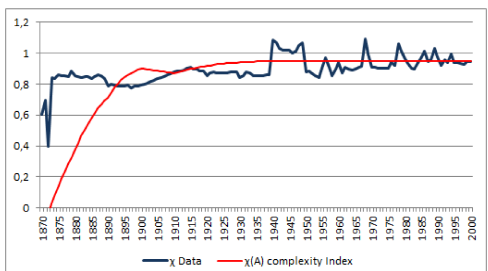

(a) Data TFP index 1870-2000; $q=3.19$ and $b=2.08$

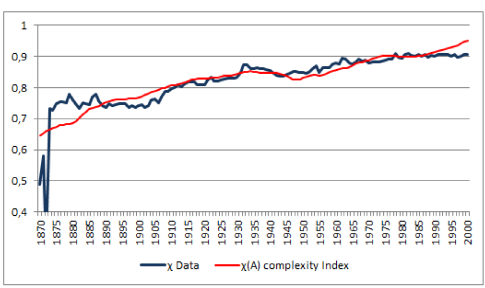

(d) Data Patent index 1870-2000; $q=1.17$ and $b=0.23$

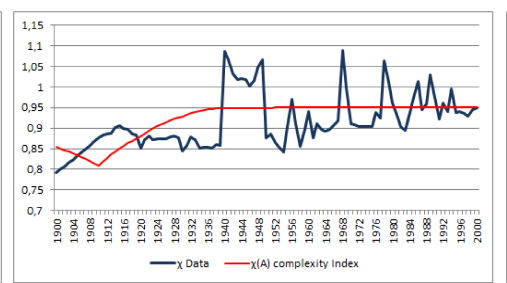

(b) Data TFP index 1900-2000; $q=2.66$ and $b=1.58$

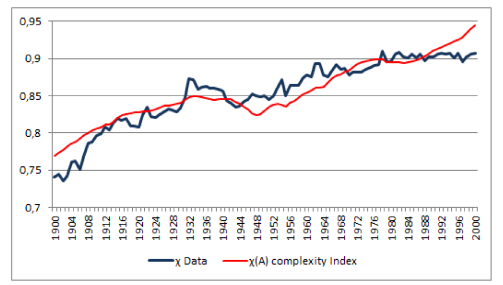

(e) Data Patent index 1900-2000; $q=1.18$ and $b=0.24$

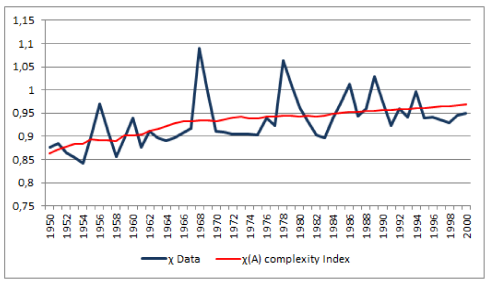

(c) Data TFP index 1950-2000; $q=1.55$ and $b=0.55$

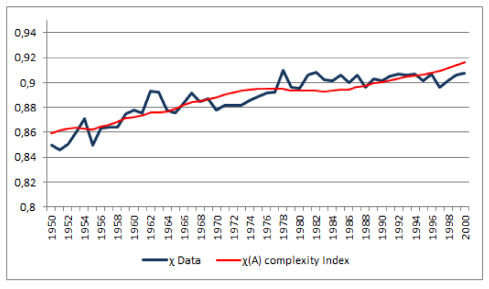

(f) Data Patent index 1950-2000; $q=1.36$ and $b=0.36$

Figure 2: Comparison between empirical series for $\chi$ (blue series) and (GMM) estimated theoretical series for $\chi(A)$ (red series)

Also, the fact that our empirical results point to $q>1$, and thus that the complexity index eventually stabilizes despite an ever-increasing number of varieties of technological goods (recall Lemma 1 and the notion of subextensive system given in footnotes 5 and 6 ), suggests an interesting discussion on what may underlie the behaviour of the index as a 'summary statistics' of the (macro) state of the economy. The stabilization of the complexity index may be interpreted as a reflexion of the fact that, in practice, new ideas (and new

\footnotetext{
${ }^{13} \mathrm{R} \& \mathrm{D}$ expenditures (as a share of output) and time are used as instruments as they are correlated with $A_{t}$, but do not directly influence the complexity effect (see equations 4 and 6 ).

${ }^{14}$ Since both the $\chi$ and A series are nonstationary, we tested for (nonlinear) cointegration. The residualbased tests of the nonlinear cointegration (with the null hypothesis specified as cointegration; e.g., Lin and Granger, 2004) suggest the existence of a nonlinear cointegration relationship in all analyzed cases. However, given the well-known challenges regarding the detection of nonlinear cointegration (e.g., Choi and Saikkonen, 2010 ) and the properties of the estimators of nonlinear regressions with nonstationary data (e.g., Park and Phillips, 2001) and also given the relatively small number of observations in our samples, the estimated confidence intervals should be interpreted with caution.
} 
varieties of technological goods) have a heterogeneous impact on complexity, with some increasing it and others decreasing it. One may notice that, historically, some inventions have reduced or attenuated the effect of complexity either directly or indirectly. Computers have allowed calculation of things and analysis of data and models in ways impossible before, while, as an indirect effect, one could argue that the development of machinery that replaces humans (e.g., earth-moving equipment) have allowed more humans to spend their time managing complexity and its effects. ${ }^{15}$

\section{$4 \quad$ Full Model}

\subsection{Households}

We consider a standard model of overlapping generations (OLG). The young generation members supply one unit of labor from which they earn wages $w_{t}$ and smooth their consumption, dividing their income between the consumption in the current period $c_{t}^{1}$ and in the second period $c_{t+1}^{1}$. Old generation members do not work and make a living from their savings. Young individuals born in period 1 maximize utility $u_{t}=\log \left(c_{t}^{1}\right)+\beta \log \left(c_{t+1}^{1}\right)$, where $\beta$ is the discount factor, subject to the following constraints: $c_{t}^{1}=w_{t}-s_{t}$, where $s_{t}$ are savings, and $c_{t+1}^{1}=r_{t+1} s_{t}$, where $r_{t+1}$ is the expected gross interest rate. This standard OLG setup provides a well-known solution for per capita savings:

$$
s_{t}=\frac{\beta}{1+\beta} w_{t} .
$$

Population has dimension $L_{t}$ and grows at an exogenous rate $n$. An exogenous population growth rate may be appropriate to include forces that enlarge the market while proving convenient in deriving analytical results and in focusing the paper on the evolution of the technology side of economic activity (for a similar approach concerning population dynamics, see Peretto, 2015).

\subsection{Firms}

A continuum of competitive firms produces a homogeneous final good using a Cobb-Douglas technology and employing physical capital, $K_{t}$, and labor, $L_{t}^{Y}$ in each period $t$ :

$$
Y_{t}=A_{t}^{\sigma} K_{t}^{\alpha} L_{t}^{Y(1-\alpha)}
$$

where $0<\alpha<1$ is the share of physical capital in national income, $1-\alpha$ the share of labor in the national income (as usual in the Cobb-Douglas settings) and $\sigma$ is a parameter that governs the returns to specialization. This allows us to proceed as Benassy (1996, 1998), Groot and Nahuis (1998) and Alvarez-Pelaez and Groth (2005) and disentangle the effect of returns to knowledge from the share of physical capital in the final good production. The physical capital $K_{t}$ is a CES aggregate of specialized capital goods, $x_{j t}$, which are the technological goods in the model:

$$
K_{t}=A_{t}\left(\frac{1}{A_{t}} \sum_{j=1}^{A_{t}} x_{j t}^{\alpha}\right)^{\frac{1}{\alpha}}
$$

\footnotetext{
${ }^{15}$ We thank John Seater for pointing this out to us. See also Iaria et al. (2018), for a more general point along these lines.
} 
For simplicity and without any loss of generality we assume that capital depreciates fully within one generation. Profit maximization yields the following first-order conditions:

$$
\begin{array}{r}
w_{t}=(1-\alpha) \frac{Y_{t}}{L_{t}^{Y}}, \\
p_{t}=\alpha \frac{Y_{t}}{K_{t}},
\end{array}
$$

where $p_{t}$ is the price of aggregated capital good. Using equations (11) and (9), we obtain the demand for individual varieties:

$$
x_{j t}=\frac{1}{A_{t}}\left(\frac{\alpha Y_{t}}{K_{t}^{\alpha} p_{j t}}\right)^{\frac{1}{1-\alpha}}
$$

where $p_{j t}$ is the price of each variety $j$ at time $t$.

In the specialized capital goods sector (in which there is monopoly power) each firm maximizes profits $\pi_{j t}=\left(p_{j t}-r_{t}\right) x_{j t}$, where $r_{t}$ is the real interest rate at time $t$, from which we obtain the usual profit maximizing price, after substituting $x_{j t}$ from equation (11), as $p_{j t}=p_{t}=r_{t} / \alpha$. Using the profits equation from the specialized capital goods sector, the profits maximizing price and equation (10) for the price, we obtain the following expression for profits, $\pi_{j t}=\pi_{t}=(1-\alpha) \alpha Y_{t} / A_{t}$. Since all varieties are produced in the same quantities, $x_{j t}=x_{t}$ and thus $K_{t}=A_{t} x_{t}$.

The number of varieties $A_{t}$ is increased according to equation (5). The free-entry condition into the R\&D sector, which only employs labor, is $w_{t} L_{t}^{A}=\pi_{t} \Delta A_{t+1},{ }^{16}$ which equates the costs and the profits of inventing $\Delta A_{t+1}$ new units. Using equation (5), this yields $w_{t} \frac{L_{t}^{\chi\left(A_{t}\right)}}{\delta A_{t}}=\pi_{t}$. We equate both equations for profits. Then we use equation (10) and the labor market clearing condition $L_{t}=L_{t}^{A}+L_{t}^{Y}$ to obtain the shares of labor employed in the $\mathrm{R} \& \mathrm{D}$ sector and in the final-goods sector: ${ }^{17}$

$$
l_{t}^{Y}=\frac{L_{t}^{Y}}{L_{t}}=\min \left\{1, \frac{1}{\alpha \delta L_{t}^{1-\chi\left(A_{t}\right)}}\right\} ; l_{t}^{A}=\frac{L_{t}^{A}}{L_{t}}=\max \left\{0,1-\frac{1}{\alpha \delta L_{t}^{1-\chi\left(A_{t}\right)}}\right\} .
$$

\subsection{Equilibrium dynamics: transitional dynamics and steady state}

Using equations (7), (8), (10), the capital market clearing condition, $K_{t+1}=L_{t} . s_{t}$, and the per capita versions of the variables as small caps of the same letters, such that $y_{t}=\frac{Y_{t}}{L_{t}}$ is per capita income, $k_{t}=\frac{K_{t}}{L_{t}}$ is physical capital per capita and $c_{t}=\frac{C_{t}}{L_{t}}$ is consumption per capita, the model can be summarized by the following equations:

\footnotetext{
${ }^{16}$ In line with, e.g., Strulik et al. (2013), we make the simplifying assumption that a patent holds for one period (i.e. one generation) and that afterwards the monopoly right to produce a good is sold at price $\pi_{t+1}$ to someone chosen at random from the next generation. Through this simplification we get rid of intertemporal (dynastic) problems of patent holding and patent pricing while keeping the basic incentive to create new knowledge intact.

${ }^{17}$ Subsidies to R\&D would enter equation (13) increasing the allocation of labor to R\&D as expected. However, due to the dynamics of the model, they can interact with the effects of population growth and the complexity effect.
} 


$$
\begin{array}{r}
s_{t}=\frac{\beta}{1+\beta} w_{t}, \\
\Delta A_{t+1}=\left(A_{t+1}-A_{t}\right)=\delta \cdot A_{t} \cdot \frac{l_{t}^{A}}{L_{t}^{\chi\left(A_{t}\right)-1},} \\
k_{t+1}=\frac{K_{t+1}}{L_{t+1}}=\frac{L_{t}}{L_{t+1}} s_{t}, \\
w_{t}=(1-\alpha) y_{t} / l_{t}^{Y}, \\
y_{t}=\left(A_{t}\right)^{\sigma}\left(l_{t}^{Y}\right)^{1-\alpha} k_{t}^{\alpha}=c_{t}+k_{t+1}, \\
L_{t+1}=(1+n) L_{t} .
\end{array}
$$

Inserting (14) into (16), then substituting $w_{t}$ from expression (17) and finally using (13) and (18), we obtain the difference equation for physical capital per capita as follows:

$$
k_{t+1}=a \frac{A_{t}^{\sigma} L_{t}^{\alpha\left(1-\chi\left(A_{t}\right)\right)} k_{t}^{\alpha}}{1+n},
$$

where $a \equiv \beta(\alpha \delta)^{\alpha}(1-\alpha) /(1+\beta)$. When $\chi(A)<1$ scale effects are present, but decreasing as $\chi(A)$ increases.

Using equations (5) and (13), we derive another difference equation that, together with equation (20), describes recursively the dynamics of this model:

$$
A_{t+1}=f\left(A_{t}, L_{t}\right)
$$

where

$$
f\left(A_{t}, L_{t}\right)= \begin{cases}A_{t} & \text { if } L_{t}^{1-\chi\left(A_{t}\right)} \leq 1 /(\alpha \delta) \\ {\left[\delta\left(L_{t}^{1-\chi\left(A_{t}\right)}-\frac{1}{\alpha \delta}\right)+1\right] A_{t}} & \text { if } L_{t}^{1-\chi\left(A_{t}\right)}>1 /(\alpha \delta)\end{cases}
$$

Notice that when the complexity index reaches unity, $\chi(A)=1$, then equations (20) and (21) become free of scale effects. When $\chi(A)<1$, scale effects are present, but decreasing as $\chi(A)$ increases. In case $\chi(A)>1$, negative scale effects arise.

In particular, $A_{t}$ follows a piecewise dynamics triggered by the (exogenous) dynamics of population, $L_{t}$, as depicted by Figure 3 and described in Lemma $3 .^{18}$

Lemma 3. A. Let $\chi\left(A_{t}\right)<1$. For a sufficiently low $L_{t}$, such that $L_{t}^{1-\chi\left(A_{t}\right)} \leq 1 /(\alpha \delta)$, equation (21) has a continuum of non-hyperbolic fixed points fully determined by the initial stock of knowledge $A_{0}$, implying that $A_{0}=A_{t}=A_{t+1}=\ldots$ ("stagnation" regime). For a sufficiently high $L_{t}$, such that $L_{t}^{1-\chi\left(A_{t}\right)}>1 /(\alpha \delta)$, there exists no fixed point and the stock of knowledge, $A_{t}$, increases at the rate $\delta\left(L_{t}^{1-\chi\left(A_{t}\right)}-\frac{1}{\alpha \delta}\right)$ ("growth" regime). B. Let $L_{t}^{1-\chi\left(A_{t}\right)} \leq 1 /(\alpha \delta)$; as long as $\chi\left(A_{t}\right)<1$, a (exogenously) growing population, $L_{t}$, will eventually move the economy from the "stagnation" to the "growth" regime. Let $L_{t}^{1-\chi\left(A_{t}\right)}>$ $1 /(\alpha \delta)$; if $\chi\left(A_{t}\right)>1$, a growing $L_{t}$ will eventually move the economy from the "growth" to the "stagnation" regime; a shift from "growth" to "stagnation" will also occur if population is constant, but $\chi(A)$ grows to $+\infty$ as $A_{t}$ (endogenously) increases.

Proof. A. In the first branch of $f\left(A_{t}, L_{t}\right)$, one gets $A_{t+1}=A_{t}$ (fixed point) with $f_{A}=1$ (non-hyperbolic) $\forall_{t \geq 0}$ in this sub-domain of $f$; in the second branch of $f\left(A_{t}, L_{t}\right)$, one gets

\footnotetext{
${ }^{18}$ This is the piecewise structure that arises in the innovation-driven endogenous growth models, such as those by Romer (1990) and Dinopoulos and Thompson (2000). This structure reflects that the R\&D cost will not be put up if the ensuing expected profit flow is not sufficiently large. In that case, there is a corner solution where investment in $R \& D$ is zero. Our paper takes this property explicitly into account to study the switch to (and from) an innovation-driven growth regime.
} 
$f_{A}>1$, implying $A_{t+1}>A_{t}, \forall_{t \geq 0}$ in this sub-domain of $f$. B. It is straightforward to see that $\partial\left[L_{t}^{1-\chi\left(A_{t}\right)}-\frac{1}{\alpha \delta}\right] / \partial L_{t}>0$ if $\chi\left(A_{t}\right)<1$ and $\partial\left[L_{t}^{1-\chi\left(A_{t}\right)}-\frac{1}{\alpha \delta}\right] / \partial L_{t}<0$ if $\chi\left(A_{t}\right)>1$ in equation (19). On the other hand, if $\chi(A)$ grows to $+\infty$ as $A_{t}$ increases, then, $\partial\left[L_{t}^{1-\chi\left(A_{t}\right)}-\frac{1}{\alpha \delta}\right] / \partial A_{t}<0$ for a given $L_{t}>1$.

For a given $\chi\left(A_{t}\right)<1$ and a sufficiently low population level, the economy may be trapped in a pre-industrial equilibrium: the low expected profits of $\mathrm{R} \& \mathrm{D}$ due to the small market scale do not cover the respective fixed costs, thus, implying no R\&D and consequently no endogenous growth. The economy exhibits a constant stock of knowledge and only the standard neoclassical transitional dynamics exists through the behavior of $k$ (see equation (20)), where the latter converges to a steady-state level. In turn, when the population is sufficiently large, the economy is in an innovation-based endogenous growth regime, as expected profits of $\mathrm{R} \& \mathrm{D}$ are large enough to match its costs. However, over time, this may occur with negative, null or positive scale effects depending on the properties of the complexity index $\chi(A)$ (see Lemmas 1 and 2), and thus the economy may converge to a steady-state zero growth (stagnation), or to a steady-state positive growth or follow an explosive growth path - the steady-state positive growth result is further detailed in Lemma 4 , below.

The phase diagram in Figure 3a shows the different possibilities for the dynamics and the steady state in this model, with an emphasis on the behavior of the stock of knowledge, which depends on the existing scale effects at each period of time, which in turn depend on the combination of $A_{t}$ and $L_{t}$.

Figure $3 \mathrm{~b}$ depicts the rotation of curve $f\left(A_{t}, L_{t}\right)$ to the left as population, $L_{t}$, exogenously grows under $\chi\left(A_{t}\right)<1$; thus, eventually, an economy initially at the "stagnation" regime will switch to the "growth" regime. The effect of exogenous population growth in this model can be somewhat compared to that in the models of Galor and co-authors (e.g., Galor and Weil, 2000; Galor and Moav, 2002), in which population growth shocks may induce a takeoff from a Malthusian trap through learning-by-doing. Here, population growth acts as a trigger for $\mathrm{R} \& \mathrm{D}$ through the effect in $\mathrm{R} \& \mathrm{D}$ returns due to scale, as long as $\chi\left(A_{t}\right)<1$, thus shifts the economy to the endogenous growth regime. This means that the economy may pass through a transition with significant positive scale effects, but which however gradually vanish over time since the complexity index $\chi\left(A_{t}\right)$ increases with $A_{t}$ (see Lemma 1). In case $\chi\left(A_{t}\right)>1$ occurs, i.e., negative scale effects arise, then population growth (or ever growing $\left.\chi\left(A_{t}\right)\right)$ will henceforth gradually reduce expected profits of $\mathrm{R} \& \mathrm{D}$. This will eventually bring R\&D to a halt and, thereby, move the economy to stagnation. This would amount to a rotation of curve $f\left(A_{t}, L_{t}\right)$ in Figure $3 \mathrm{~b}$ to the right (not shown) towards the $A_{t+1}=A_{t}$ locus. In order to analyze these effects quantitatively, Section 5, below, will consider historical data on population growth rates to calibrate the model.

Besides the dynamics of population, a move from the "stagnation" to the "growth" regime may be accomplished through a positive exogenous shock on the available initial stock of knowledge (e.g.,, sudden openness of the economy to foreign direct investment or imports of technology) or through subsidies to R\&D, which lower the threshold in equation (21). ${ }^{19}$ This type of regime shift (due to exogenous effects) may well represent episodes of late industrialization.

Lemma 4 characterizes the conditions for a feasible steady state with endogenous growth and increasing population.

\footnotetext{
${ }^{19}$ In Section 5.1.2, below, we will extend the model to a setting with a knowledge production function also featuring international knowledge diffusion.
} 


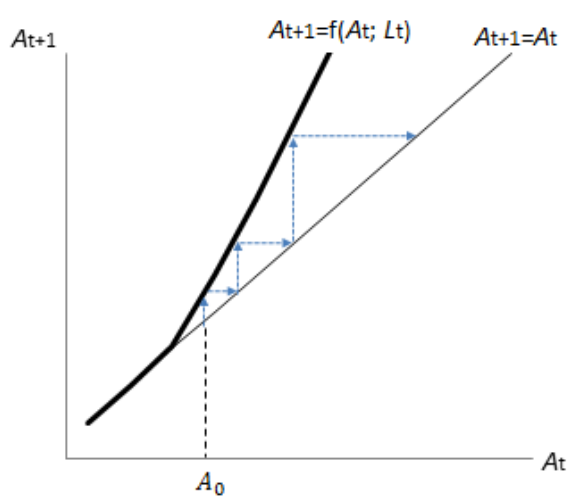

(a) This figure depicts the piecewise dynamics in the stock of knowledge, $A_{t}$, for a given $L_{t}$; in the first branch of $f\left(A_{t}, L_{t}\right)$, with $f_{A}=1$, there is a continuum of fixed points implying stagnation in $A$ ("stagnation" regime); in the second branch, with $f_{A}>1$, there are no fixed points and $A$ grows endogenously ("growth" regime).

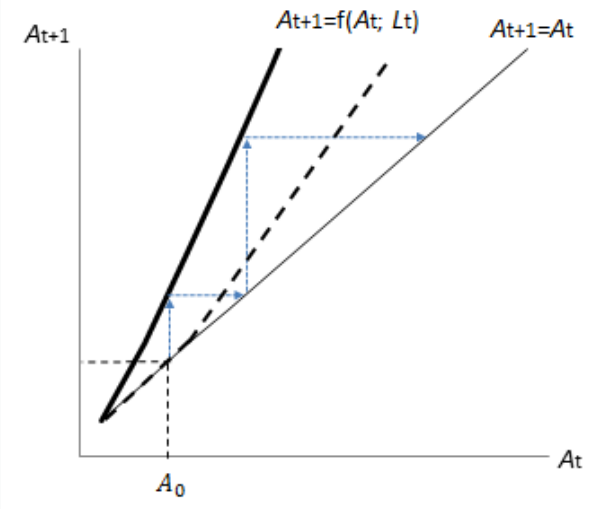

(b) This figure depicts the rotation of curve $f\left(A_{t}, L_{t}\right)$ to the left as population, $L_{t}$, exogenously grows under $\chi\left(A_{t}\right)<1$ (curve $f\left(A_{t}, L_{t}\right)$ in panel (a) appears as a dashed kinked curve in panel (b)); thus, eventually, an economy initially at the "stagnation" regime will switch to the "growth" regime.

Figure 3: Phase diagrams for the stock of knowledge.

Lemma 4. With increasing population, only $\chi\left(A_{t}\right)=1$ guarantees a feasible steady state with positive growth; consequently $g_{A_{t}}^{*}=\frac{\Delta A_{t+1}}{A_{t}}=\left(\delta-\frac{1}{\alpha}\right)$ and $g_{k_{t}}^{*}=\frac{\Delta k_{t+1}}{k_{t}}=\left(\frac{\sigma}{1-\alpha}\right)\left(\delta-\frac{1}{\alpha}\right)$ , and there is a feasible steady state with endogenous growth if and only if $\delta \alpha>1$.

Proof. Substitute $\chi\left(A_{t}\right)=1$ in equation (18) and in equation (19).

This model evolves to a steady state characterized by endogenous economic growth, depending only on the primitive parameters of the model, if $\chi\left(A_{t}\right)$ converges to a constant equal to unity (i.e., scale effects vanish) under increasing population. The phase diagram, in Figure 4, shows the asymptotic steady state for a constant $\chi\left(A_{t}\right)$. In that case, it should be noted that only neoclassical transitional dynamics exists, through the behavior of $g_{k}$. This highlights the importance of the state-varying time-dependent complexity effect to provide technological transitional dynamics.

From equations (20) and (21) and recalling Lemmas 1 and 2, we see that the result in Lemma 4 occurs for a combination of the parameters of the entropy function in equation (4) such that $q>1$ and $b=q-1$, i.e., the complexity index $\chi\left(A_{t}\right)$ converges to a constant equal to unity, implying null scale effects. Also for $q>1$, the complexity index $\chi\left(A_{t}\right)$ converges to a constant smaller than unity if $b<q-1$, or larger than unity if $b>q-1$, implying, respectively, some positive or negative scale effects. In these cases, steady-state positive growth arises only if population is constant. With increasing population, the growth rate will follow an explosive path in the former case and converge to steady-state zero growth in the latter. Finally, for $q \leq 1$, growth vanishes to zero as the stock of knowledge increases over time and the complexity index, $\chi\left(A_{t}\right)$ goes to $\infty$, even under constant population. ${ }^{20}$ This means that the model is flexible enough to replicate different outcomes, depending on the quantitative calibration of the knowledge production function.

In the next Section, we calibrate the model and evaluate quantitatively the plausible behavior of the economy governed by this model. We also use that calibrated model to evaluate

\footnotetext{
${ }^{20}$ In sum, the economy can stagnate due to: (i) increasing population and $\chi(A)>1$, with $\chi(A)$ converging to a constant larger than unity $(b>q-1$ and $q>1$ ), or (ii) increasing technological progress (even with constant population) and $\chi(A)>1$, with $\chi(A)$ going to infinity $(q \leq 1)$. In both cases, given the piecewise structure of equation (21), stagnation will occur in finite time.
} 


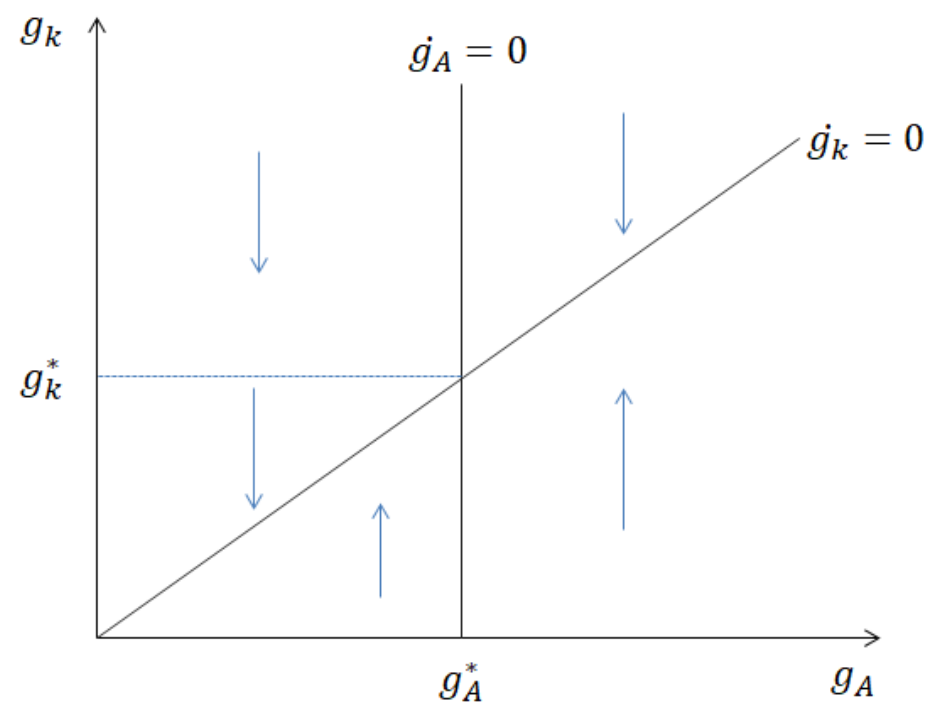

Figure 4: Phase diagram for the asymptotic steady-state, with $\chi\left(A_{t}\right)$ constant equal to unity and increasing population (or with $\chi\left(A_{t}\right)$ constant different from unity, but constant population).

how the economy behaves toward the future under different scenarios for the calibration of the complexity 'operator'.

\section{Calibration and the evolution of this economy}

The value for the share of physical capital is often regarded as constant, around 0.36, as a stylized fact, since Kaldor (1961). Thus we use $\alpha=0.36$. Elsby et al. (2013) present values for the labor share that support this choice. We use $\beta=0.216$, which replicates a gross domestic savings rate (as a percentage of GDP) in the United States of $21 \%$ (average between 1974 and 2013). We take the value for returns to knowledge $\sigma=0.2$ from Coe et al. (2009: Table 4) for the group of G7 countries with the larger updated sample considered in that article. This value is consistent with the average empirical values for the output elasticity to R\&D yielded by country studies reported in Hall et al. (2009: Table 5), which oscillate between of 0.18 (considering only domestic R\&D) and 0.235 (considering both domestic and international R\&D), using estimates for the group of OECD and G-7 countries. We set the value of $\delta$ (productivity in the R\&D sector) such that the model replicates an annual average growth of GDP per worker in the United States of 1.87\% (average between 1950 and 2000) in the steady state of the endogenous-growth case without scale effects (please see Lemma 4). The values that shape the entropy function for the complexity effect - equation (3) - come from the empirical exercise shown in Section 3 and are depicted in Table 2, below. As can be observed in Table 1, there are several of those estimations that yield very similar results. Thus, we selected a set of estimated values that exemplifies the possible different patterns of the economy, including the cases where $b>q-1, b<q-1$ and $b=q-1$. The summary of the considered estimated values for these crucial parameters is presented in Table 2. To sum up: (i) the utility discount factor, $\beta$, and the productivity in $\mathrm{R} \& \mathrm{D}, \delta$, are chosen to replicate respectively a savings rate of $21 \%$ and an economic growth rate of $1.87 \%$ in the steady state, which are values from the United States statistics; (ii) the share of physical capital in income, $\alpha$, and returns to knowledge, $\sigma$, are calibrated using values consistent with empirical literature; (iii) $q$ and $b$ come from the econometric estimations of the complexity 
effect presented in Section $3 .^{21}$ We include a series for the growth rate of population $n_{t}$ from Maddison (2008), taking the average growth rate for each generation of 20 years, considering the population values for 12 countries in western Europe (Austria, Belgium, Denmark, Finland, France, Germany, Italy, Netherlands, Norway, Sweden, Switzerland and the United Kingdom), the United States, and Australia.

In the numerical exercise we show results for the path of the economy in the postindustrial revolution, beginning in $1860 .{ }^{22}$ In this case we want to replicate the main facts of the evolution of the economy in this period and will also compare the evolution of the "model" series with "data" series. Note that as we do not make any assumption on the values that govern the complexity index $\chi(A)$ our objective is also to replicate the empirical value for $\chi(A)$, in 2000 , which is clearly around one.

Table 2: Values of complexity parameters in calibration

\begin{tabular}{cc}
\hline \hline & \\
Estimated Complexity Parameters $(q ; b)$ & Sources for $(q ; b)$ \\
\hline \hline$(2.47 ; 1.4)$ & Average Figs. 2a, 2b and 2c \\
\hline$(1.17 ; 0.23)$ & Fig. 2d \\
\hline$(1.36 ; 0.36)$ & Fig. 2f \\
\hline \hline
\end{tabular}

\subsection{From the Industrial Revolution to the present days}

In this subsection we will present the results of our simulations in our benchmark model. We compare the series for TFP growth, GDP per capita growth and GDP per capita levels, and the complexity (entropy) effect that emerges from the model with the series found in data. For GDP per capita growth and GDP per capita levels in the data, ${ }^{23}$ we use series for the United States and an average of 12 European countries and the United States and Australia (the same average as we used to input exogenous population growth series in the simulation), from Bolt and van Zanden (2014) - or the Maddison Project - and series for the United Kingdom from Clark (2009). For TFP growth we use series for the United States (already used in Section 3) and for the United Kingdom from Clark (2009). Finally, we compare the model complexity effect with the series we have calculated as explained in Section 3.

Figure 5 shows our main results. The model replicates an acceleration of TFP growth which tends to stabilize over the second half of the $\mathrm{XX}^{\text {th }}$ century. Especially when comparing TFP model series with data series, it is worth noting that the model has not the sufficient ingredients to replicate the empirical effect of the Great Depression between the 1920 and 1940 generations. ${ }^{24}$ Despite that, the model approximate quite well the evolution of the growth rate of per capita output, showing clearly the acceleration due to the industrial revolution. Also as the income growth rate accelerates until the generation of the 1920s, it approaches the replication of the "roaring twenties", which is also seen in the data (see Figure 5c). Furthermore, the growth rate also decelerates in the 1940s, corresponding to

\footnotetext{
${ }^{21}$ In the Appendix B, we test the robustness of the results to the consideration of an alternative higher value of $\sigma$. This alternative value also allows for the estimation of parameters $q$ and $b$ that adjust well the theoretical value of the complexity effect to the empirical series for $\chi$ - see Figure 14 .

${ }^{22}$ As Mokyr (2005) argued, during the early stages of the Industrial Revolution propositional knowledge originated new techniques mostly based on pragmatic, informal, intuitive, and empirical skills. According to the author the R\&D activity resting on industry-based science emerged not before the mid-XIX ${ }^{t h}$ century.

${ }^{23}$ In the case of the level of GDP per capita we normalize the data and model values to 100 in 1860. Growth rates are gross growth rates for one generation, 20 years.

${ }^{24} \mathrm{~A}$ stylized model of endogenous growth as this one intends to replicate the long-run stylized facts (also those affecting the transitional dynamics) and not cyclical phenomena. In fact, most countries have returned to their long-run trend of long-run growth after the Great Depression.
} 


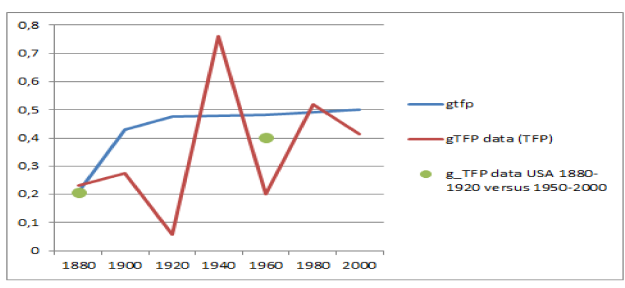

(a) TFP growth; gTFP data is averaged from the United States (own data) and from the United Kingdom - Clark (2009); g_TFP data USA 18801920 versus 1950-2000 are averages of the United States TFP growth rates over 50-year periods to avoid the effects of the Great Depression and World Wars.

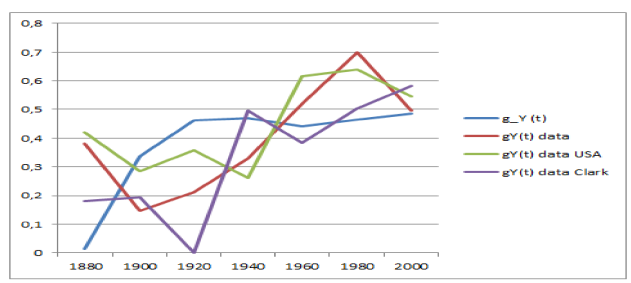

(c) GDP per capita growth rates; $g Y(t)$ data is for average of countries (see text) and $g Y(t)$ data $U S A$ is from Maddison Project and $g Y(t)$ data Clark is data for the United Kingdom from Clark (2009).

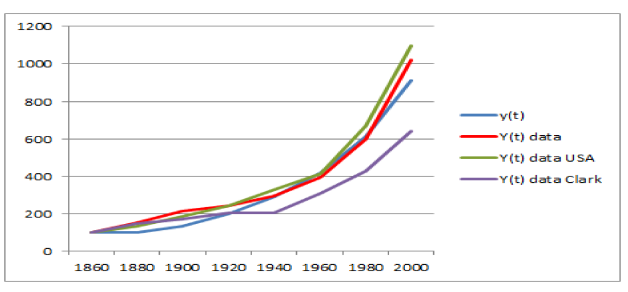

(b) GDP per capita levels; $Y(t)$ data is average of countries (see in the text) and $Y(t)$ data USA are from Maddison Project and $Y(t)$ data Clark is data for the United Kingdom from Clark (2009).

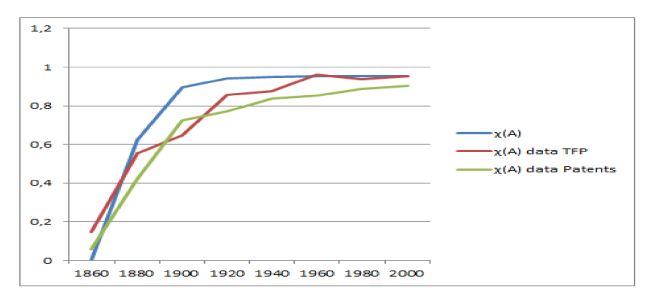

(d) Complexity Effect $\chi(A) ; \chi(A)$ data TFP and $\chi(A)$ data Patents are respectively from TFP data and Patents data as calculated in Section 3.

Figure 5: Evolution of the main "model" series (blue line series) and comparison with "data" series $\left(q=2.47\right.$ and $\left.b=1.4, k_{0}=0.025, L_{0}=0.75, A_{0}=1\right)$.

the historical period of the II World War. Note that after the 1960s, although accelerating as in the data, the growth rate underperforms when compared to data, but it also does not present the deceleration that the "Maddison Project" data show for the generations after the 1980s. In fact, this simulation does not completely account for the acceleration of the growth rates following the World War II. Regarding the level of per capita GDP, the model almost mimics the evolution of the data for the average of countries and is slightly below the data for the United States. Figure 5d shows that the evolution of the complexity effects closely follows the data we obtained for this effect, and is particularly close to the data for the complexity effect obtained from the TFP data. It is interesting to note that a lower complexity effect has two reinforcing effects: while it increases TFP growth, it also increases capital growth due to a stronger scale effect, as the lower the complexity effect the higher the scale effect on growth. An alternative value of the returns to knowledge, higher than the empirical values found in the literature (but used e.g. in Jones and Williams, 2000) is used in simulations presented in Appendix B. Those simulations indicate that the theoretical economy adjusts worse to the empirical series. This is consistent with the fact that the 0.2 value for $\sigma$ used in the baseline exercises is within the available estimated intervals for returns to knowledge.

It is worth noting that with some variations in the parameters of the complexity function we can replicate the productivity (TFP) slowdown after the 1940's (intensified after the 1960s) and the main pattern related to the evolution of the other variables. In Figure 6 we show the evolution of the main variables in the economy for alternative estimates of $q=1.17$ and $b=0.23$. Note that according to Lemma 1 the complexity effect converges to a value higher than one in this case, guaranteeing endogenous growth in the steady state with (small) negative scale effects. In this figure the pattern of the evolution of TFP growth is much closer to the data series reflecting a very pronounced TFP slowdown after the 1960s. 
The evolution of GDP per capita growth rates also replicates better the data growth rates of the second half of the $\mathrm{XX}^{t h}$ century becoming very close to the US data values, while maintaining a good fit to the previous growth rate evolution from the end of the XIX ${ }^{t h}$ century. In fact, in this case the underperformance of output growth rates in the 1960s is quite reduced when compared with the previous simulation. GDP per capita levels are again close to the United States data. In this case, the model series almost overlaps the data series. The complexity effect $\chi(A)$ is slightly above the value of one in 2000, also close to the data. ${ }^{25}$

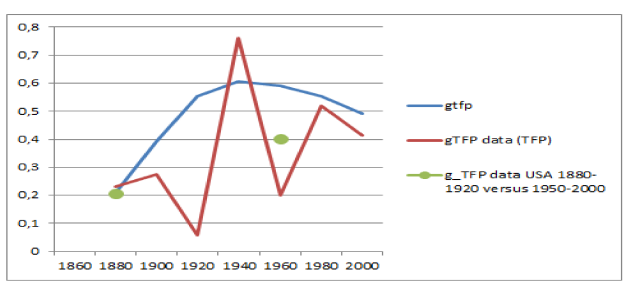

(a) TFP growth; $g$ TFP data is averaged from the United States (own data) and from the United Kingdom - Clark (2009); g_TFP data USA 18801920 versus 1950 -2000 are averages of the United States TFP growth rates over 50-year periods to avoid the effects of the Great Depression and World Wars.

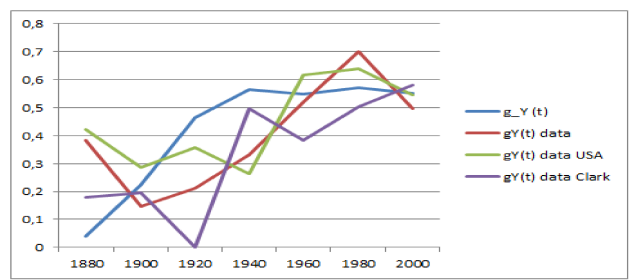

(c) GDP per capita growth rates; $g Y(t)$ data is for average of countries (see text) and $g Y(t)$ data $U S A$ is from Maddison Project and $g Y(t)$ data Clark is data for the United Kingdom from Clark (2009).

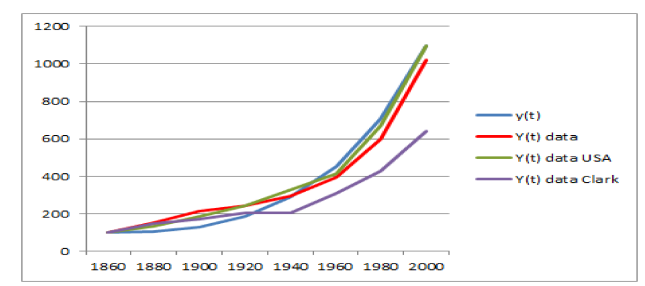

(b) GDP per capita levels; $Y(t)$ data is average of countries (see in the text) and $Y(t)$ data USA are from Maddison Project and $Y(t)$ data Clark is data for the United Kingdom from Clark (2009).

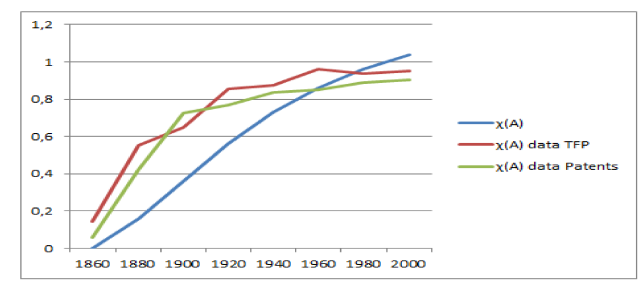

(d) Complexity Effect $\chi(A) ; \chi(A)$ data TFP and $\chi(A)$ data Patents are respectively from TFP data and Patents data as calculated in Section 3.

Figure 6: Evolution of the main "model" series (blue line series) and comparison with "data" series $\left(q=1.17\right.$ and $\left.b=0.23, k_{0}=0.025, L_{0}=0.75, A_{0}=1\right)$.

In Figure 7, we present an example in which the limit of the complexity index is one (recall Figure 1 ), with $q=1.36$ and $b=0.36$, a possibility that was also yielded by the estimations of the complexity function shown in Section 3. This simulation not only depicts an episode similar to the productivity slowdown after the 1940s, intensified after the 1960s, as the data also shows, but it also replicates the acceleration of growth rates until the 1940s, a very slight slowdown after the 1940s, corresponding to the period of the II World War, which is followed by a recovery afterwards (see Figure 7c), being close to the data growth rates data. The model series for GDP per capita (blue series in Figure 7b) in this case is (again) almost overlapping the series from the average of countries from the Maddison Project. Figure $7 \mathrm{~d}$ shows that the simulated complexity effect is again very close to the empirical estimated values.

In Figure 8, we present an example in which the limit of the complexity index is infinity (recall Figure 1), with $q=0.99$ and $b=0.14$. It should be noted that our empirical estimations do not support the case for $q<1$. However, due to the relatively small number of observations and the cautiousness with which the confidence intervals should be regarded

\footnotetext{
${ }^{25}$ In Figures 2c and 14c, one can observe that some values of the complexity effect are higher than 1 in some years after the second half of the $\mathrm{XX}^{\text {th }}$ century.
} 


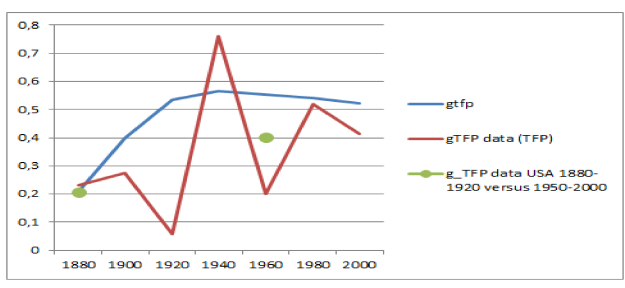

(a) TFP growth; gTFP data is averaged from the United States (own data) and from the United Kingdom - Clark (2009); g_TFP data USA 18801920 versus 1950-2000 are averages of the United States TFP growth rates over 50-year periods to avoid the effects of the Great Depression and World Wars.

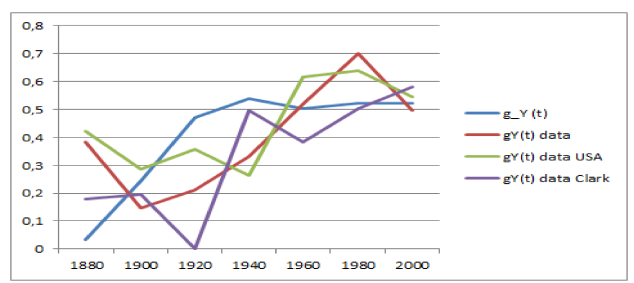

(c) GDP per capita growth rates; $g Y(t)$ data is for average of countries (see text) and $g Y(t)$ data $U S A$ is from Maddison Project and $g Y(t)$ data Clark is data for the United Kingdom from Clark (2009).

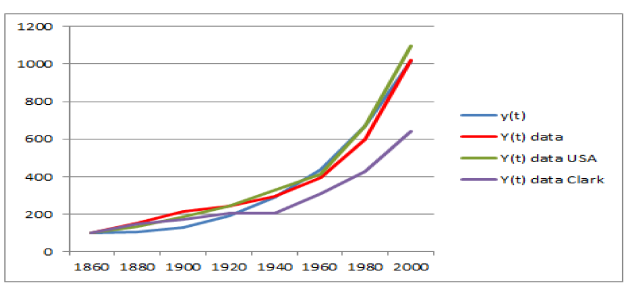

(b) GDP per capita levels; $Y(t)$ data is average of countries (see in the text) and $Y(t)$ data USA are from Maddison Project and $Y(t)$ data Clark is data for the United Kingdom from Clark (2009).

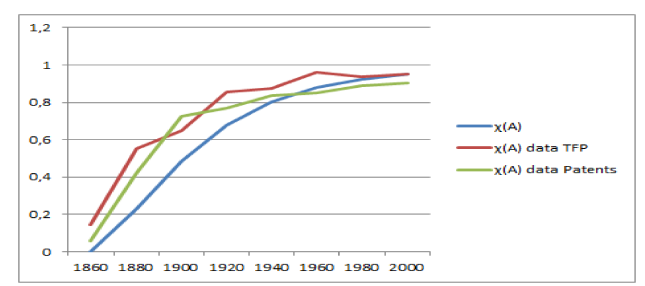

(d) Complexity Effect $\chi(A) ; \chi(A)$ data TFP and $\chi(A)$ data Patents are respectively from TFP data and Patents data as calculated in Section 3.

Figure 7: Evolution of the main "model" series (blue line series) and comparison with "data" series $\left(q=1.36\right.$ and $\left.b=0.36, k_{0}=0.025, L_{0}=0.75, A_{0}=1\right)$.

(already mentioned in Section 3) and also the fact that, in some estimations the value for $q$ is already close to one, we think it would be interesting to present such an exercise. In particular we consider a value of $q$ sufficiently close to 1 (0.99) and then adjust $b$ such that the series for TFP growth exactly replicates the data value in 2000. In consequence, we obtain $b=0.14$. Interestingly, this parameterization yields a trajectory of the economy which replicates very well the data on output per capita growth rates and levels as well as TFP growth rates. The replication of output growth rates is particularly impressive after the 1960s, with a slight acceleration followed by a slowdown after the 1980s. Nevertheless, it also implies that the complexity effect slightly surpasses the empirical value in the years 2000 .

In the next Section we will present counterfactual exercises to evaluate the importance of considering a varying state-dependent complexity effect to approximate the transitional dynamics of the model with the data series.

\subsubsection{Counterfactual exercises with no varying complexity effect}

Now, we wish to show the relevance of considering a time-varying state-dependent complexity effect in the R\&D technology that we have introduced, which implies that the scale effects gradually vanish. Firstly we assume that the complexity effect $\chi(A)$ is always one, which implies that there are no scale effects throughout history. Secondly, we consider that $\chi(A)=0$ always, which implies maximum scale effects throughout history. Both exercises show us the plausibility of considering a time-varying and increasing complexity effect in R\&D. In the first case (Figure 9a), the main implausible prediction of the model is that the growth of TFP would always be constant from 1860 to 2000 - i.e., there would be no transitional dynamics in the stock of knowledge. As we have mentioned before, the complexity effect due to entropy is the mechanism that leads to technology transitional dynamics in 


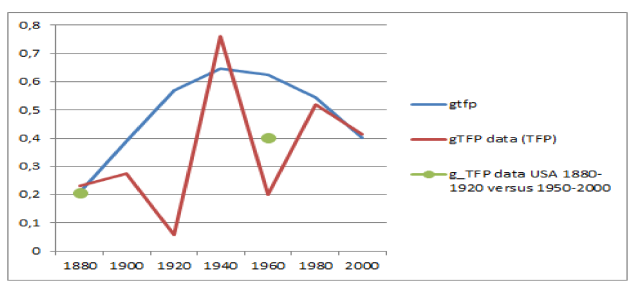

(a) TFP growth; gTFP data is averaged from the United States (own data) and from the United Kingdom - Clark (2009); g_TFP data USA 18801920 versus $1950-2000$ are averages of the United States TFP growth rates over 50-year periods to avoid the effects of the Great Depression and World Wars.

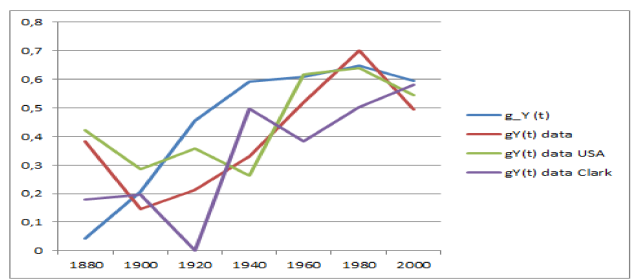

(c) GDP per capita growth rates; $g Y(t)$ data is for average of countries (see text) and $g Y(t)$ data $U S A$ is from Maddison Project and $g Y(t)$ data Clark is data for the United Kingdom from Clark (2009).

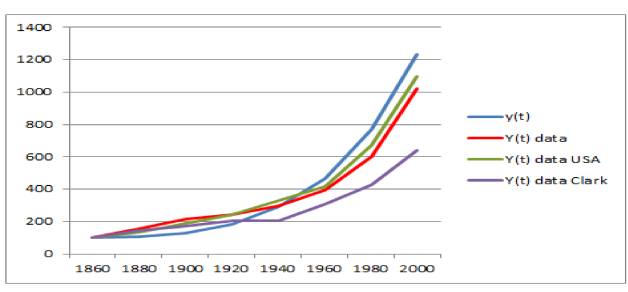

(b) GDP per capita levels; $Y(t)$ data is average of countries (see in the text) and $Y(t)$ data USA are from Maddison Project and $Y(t)$ data Clark is data for the United Kingdom from Clark (2009).

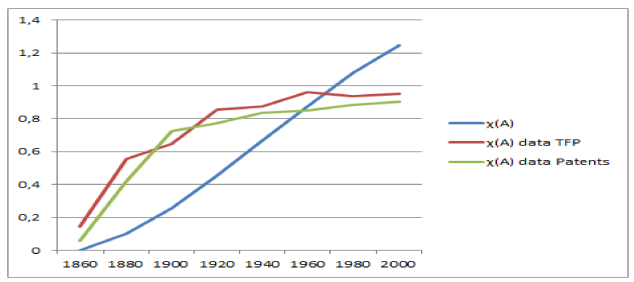

(d) Complexity Effect $\chi(A) ; \chi(A)$ data TFP and $\chi(A)$ data Patents are respectively from TFP data and Patents data as calculated in Section 3.

Figure 8: Evolution of the main "model" series (blue line series) and comparison with "data" series $\left(q=0.99\right.$ and $\left.b=0.14, k_{0}=0.025, L_{0}=0.75, A_{0}=1\right)$.

this model. In fact, also in growth rates of per capita output, the model with a constant complexity effect of one would fail to replicate the evolution after the industrial revolution, yielding economic growth rates almost constant throughout this 200 year period of history. ${ }^{26}$ In the second exercise with full scale effects (Figure 9b) the growth of TFP is always much higher than the data show, and instead of slowing down after 1980, it increases a great deal. In 2000 the growth rate of TFP would be implausibly high (near an annualized rate of $3.69 \%$, while in data it is close to an annualized rate of $1 \%$ ). ${ }^{27}$ Additionally, by assumption, we are imposing a complexity effect of zero, which is counterfactual in face of the evidence we showed in Section 3.

In the next subsection we introduce a modification in the knowledge production function such that it may benefit from knowledge diffusion across borders (as e.g., in Bottazzi and Peri, 2007 and Ang and Madsen, 2015). Our aim is to test the robustness of our results to this change in the setup, as the use of foreign ideas could diminish the importance of the complexity effect and eventually overcome it.

\subsubsection{International knowledge diffusion}

In this subsection we change the knowledge production function to the more general specification

$$
\Delta A_{t+1}=\delta\left(A_{t}\right)^{\phi}\left(A_{t}^{w}\right)^{\mu} \frac{L_{t}^{A}}{L_{t}^{\chi\left(A_{t}\right)}},
$$

\footnotetext{
${ }^{26}$ The Figure for GDP per capita growth rates is not shown, but it is available upon request.

${ }^{27}$ We should note that the changes in the assumptions about the complexity effect have no effect in the steady-state growth rate of $1.87 \%$ that we replicate.
} 


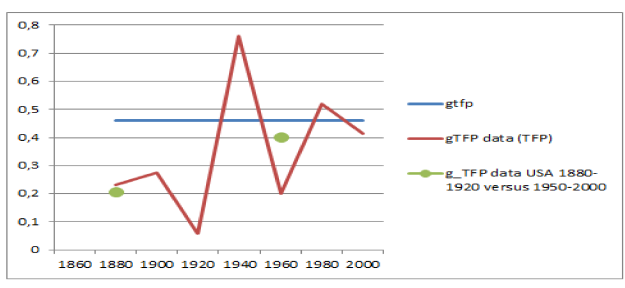

(a) TFP growth; gTFP data is averaged from the United States (own data) and from the United Kingdom - Clark (2009); g_TFP data USA 18801920 versus 1950-2000 are averages of the United States TFP growth rates over 50-year periods to avoid the effects of the Great Depression and World Wars.

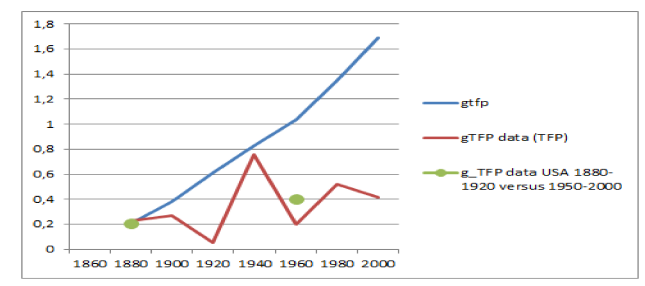

(b) TFP growth; gTFP data is averaged from the United States (own data) and from the United Kingdom - Clark (2009); g_TFP data USA 18801920 versus 1950-2000 are averages of the United States TFP growth rates over 50-year periods to avoid the effects of the Great Depression and World Wars.

Figure 9: Evolution of the "model" series (blue line series) and comparison with "data" TFP series (imposed $\chi(A), k_{0}=0.025, L_{0}=0.75, A_{0}=1$ ).

where, in addition to the specification in equation (5), we include domestic knowledge spillovers controlled by $\phi(\leq 1)$ and international knowledge, $A_{t}^{w}$, following Bottazzi and Peri (2007) and Ang and Madsen (2015). This last term represents an exogenous and foreign stock of ideas influencing the production of domestic new technologies. ${ }^{28}$ The degree of international spillovers is controlled by $\mu(\geq 0)$. In order to measure $A_{t}^{w}$ we use the stock of patents issued to non-residents in the United States (registered in the United States patent office). First we set $A_{0}^{w}$ equal to the data ratio between patents issued to non-residents in the United States and patents issued to residents in the United States in 1860 (the first observation in the simulations), which was $1.0079 \%$. Then, we calculate the growth rate of $A_{t}^{w}$ as the growth rate of the stock of patents issued to non-residents in the United States in the country patent office. We use the resulting exogenous series as an input to the simulation. We set $\phi=0.985$ and $\mu=0.035$, resulting from the estimates in Ang and Madsen (2015, Table 1, column 4). ${ }^{29}$ Moreover, the coefficient for international spillovers is the resulting sum of all the coefficients pertaining to external influences (international issued patents, foreign direct investment and imports). ${ }^{30}$ Figure 10 shows the results.

In Figure 10 we can observe that this extension shows the robustness of our main results to a more complete knowledge production function, which also includes international knowledge spillovers. In fact, the simulation mimics quite well the final growth rates (both for GDP per capita and TFP) in 2000 and plots a slight recovery between 1980 and 2000. It decreases the fit to the data on output growth rates in the period between 1960 and 1980, as it now predicts a slight slowdown. This is due to the decrease in the patenting activity of the foreigners in the United States in these decades. Finally it also mimics quite well the evolution of the complexity effect. Thus, we conclude that the modification of the model to account for foreign knowledge diffusion does not diminish the accuracy of the model in replicating the complexity effect or the growth rates and approximates the evolution of GDP per capita. In this case the model evolution of GDP per capita is between the United Kingdom data in Clark (2009) and the averaged data for the developed countries.

Overall we show that our model with a state-dependent, time-varying complexity effect

\footnotetext{
${ }^{28}$ This extension encompasses a k.p.f. with decreasing returns to the stock of knowledge due to two components: $\phi<1$ (as in Jones, 1995) and the complexity effect introduced in this paper, $\chi(A)$. The derivation of the model with this change in the k.p.f. is presented in the Appendix.

${ }^{29}$ We use the estimates that did not include human capital in the regressions as our model also does not include human capital.

${ }^{30}$ The coefficient on international issued patents is negative in Ang and Madsen (2015). Then, as our model does not incorporate other international influences than international issued patents, $A_{t}^{w}$, it seems appropriate to attribute to that model term all the coefficient values pertaining to international influences. In fact, when ignoring foreign direct investment and trade, as Botazzi and Perli (2007) did, the coefficient on $A_{t}^{w}$ would turn positive.
} 


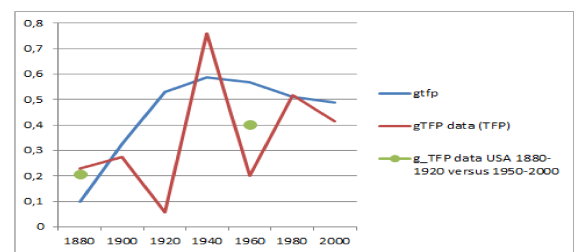

(a) TFP growth; gTFP data is averaged from the United States (own data) and from the United Kingdom - Clark (2009); $g_{-}$TFP data USA 1880-1920 versus 1950-2000 are averages of the United States TFP growth rates over 50-year periods to avoid the effects of the Great Depression and World Wars.

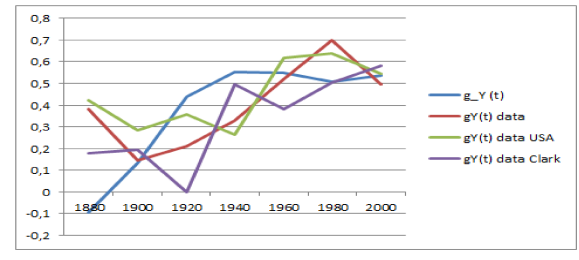

(c) GDP per capita growth rates; $g Y(t)$ data is for average of countries (see text) and $g Y(t)$ data USA is from Maddison Project and $g Y(t)$ data Clark is data for the United Kingdom from Clark (2009).

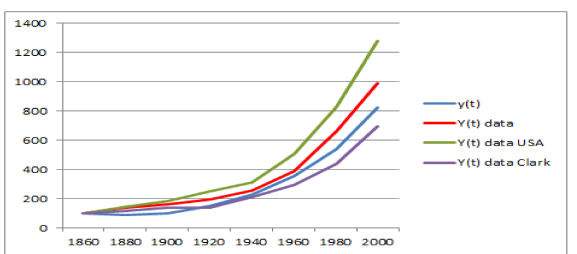

(b) GDP per capita levels; $Y(t)$ data is average of countries (see in the text) and $Y(t)$ data $U S A$ are from Maddison Project and $Y(t)$ data Clark is data for the United Kingdom from Clark (2009).

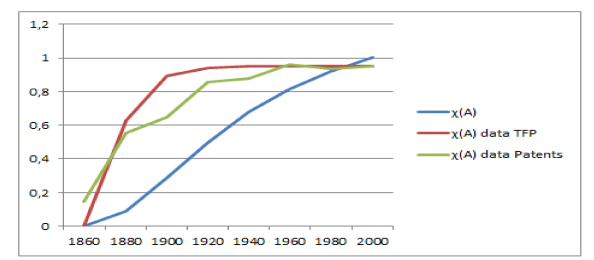

(d) Complexity Effect $\chi(A) ; \chi(A)$ data TFP and $\chi(A)$ data Patents are respectively from TFP data and Patents data as calculated in Section 3.

Figure 10: Evolution of the "model" series (blue line series) and comparison with "data" series $\left(q=1.17\right.$ and $\left.b=0.23, \phi=0.985, \mu=0.035, k_{0}=0.025, L_{0}=0.75, A_{0}=1\right)$.

due to entropy can mimic the main patterns of the data as regards the evolution of the growth rate and level of GDP per capita and can also account for the productivity slowdown. Additionally, it is also consistent with a complexity effect that approaches one as the economy gets to 2000 . These main results are maintained when international spillovers are considered in the knowledge production function. It is also worth noting that the parameterization of the complexity function determines the strength of the productivity slowdown at the end of the $\mathrm{XX}^{\text {th }}$ century. In particular, variations in the parameterization of the complexity function based on empirical estimations show the fit of the model to the TFP growth, highlighting the productivity slowdown of the late $\mathrm{XX}^{\text {th }}$ century and without compromising the fit of the model to the other variables. ${ }^{31}$

\subsection{Futuristic Scenarios}

Gordon (2012) conjectures that the world economy will face a secular slowdown in the XXI ${ }^{\text {th }}$ century using what he called to be a "provocative exercise in subtraction". In this Section,

\footnotetext{
${ }^{31}$ In an earlier working-paper version of this article (available at http://wps.fep.up.pt/wps/wp575.pdf), we devise an extension to our model with a time-varying state-dependent knowledge spillover in the knowledge production function, modelled as a "network/globalization effect" as a function of the aggregate stock of capital - see Strulik (2014) for detailed foundations for such a specification. This version of the model sets side-by-side a complexity-effect index (the exponent $\chi(A)$ of $1 / L_{t}$, as in eqs. (5) and (22)), which increases over time due to an increasing $A$, and a globalization-effect index (appearing as an exponent of $A_{t}$ ), which increases over time due to an increasing $k$. This specification is consistent with the empirical time series retrieved from an accounting exercise as the one carried out in Section 3, which show increasing empirical measures of both exponents over time. An alternative specification considering say $(1-\chi(A))$ as an exponent of $A_{t}$ (alongside $\chi(A)$ as an exponent of $1 / L_{t}$ ) is not consistent with the empirical time series because the accounting exercise again shows an increasing empirical measure of the exponent of $A_{t}$, which in this case implies a decreasing (empirical) complexity index, whereas the (theoretical) complexity function $\chi(A)$ increases with an increasing $A$. This suggests that a theory of complexity/entropy is adequate to model the exponent of $1 / L_{t}$, while a theory of network/globalization effects seems adequate to model the exponent of $A_{t}$. We obtain a globalization-effect index that is close but smaller than unity for most of the period corresponding to the $\mathrm{XX}^{t h}$ century, while the complexity function continues to feature an estimated $q>1$, as obtained in the baseline model.
} 
we extend the previous scenarios to the future and, interestingly, we conclude that the model predicts a significant slowdown of the economy (in per capita output) after 2000. We do insample calibration in our theory and extend the series without any other assumption on the dynamics of the model. According to demographic projections, population growth rates will tend to stagnate as fertility rates decrease and tend to stabilize at around 2.1 children per woman. We use Maddison's (2008) projections for population until 2030 (for the observation for 2020s generation), using population for the same countries as before and then steadily decrease population growth by 0.01 percentage points in each 20 -year period until it reaches zero in 2820. The results presented below emphasize the time path of the growth rates of the main variables and of the level variables linked with the knowledge sector. Figure 11 shows the results for the first parameterization of the complexity function $(q=2.47$ and $b=1.4$, thus $\lim _{A \rightarrow+\infty} \chi(A)=0.952<1$ ). This first scenario, corresponding to our first parameterization that replicates well the evolution of growth rates until the 1960s (date after which the model underestimates the growth rates acceleration shown by the data), predicts that, after a slowdown corresponding to the period of the II World War, growth would continue to accelerate until 2020, after which it decreases nearly 2.2 percentage points (p.p.) in 20 years, then slightly increases and eventually stabilizes around 2700 (not shown in the figure). This dynamics is due to physical capital and to R\&D. The neoclassical effect determines the drop in growth rates in the 1940s, since the physical capital growth rate drops 8 p.p. between 1940 and 1960. Then its growth rate steadily increases by near 17 p.p. until 2020. After the 2020s, the model predicts a decrease in the physical capital growth rates evaluated in 10 p.p. The model estimates that after the 1920s the long-run behavior of $R \& D$ changed dramatically and research increases at a much lower rate than before, but grows steadily until the end of the millennium. The steady state will occur then with an allocation of labor to R\&D that remains constant after near the 2700s.

Our second scenario extends our second exercise in Section 5.1, which uses $q=1.17$ and $b=0.23$ estimates, yielding $\lim _{A \rightarrow+\infty} \chi(A)=1.3529>1$ (Figure 12). In this case, the output growth rate slightly diminishes between 1980 and 2000, which is also confirmed by the data (near 1.5 p.p. in 20 years). This fall continues and doubles (to 3 p.p.) between 2000 and 2020. This growth rate will then decrease steadily and stagnation will eventually set in on the eve of 2500 A.D. After the recovery of the physical capital growth rate happened after the 1960s, it begins the downward trend after 2020. Moreover, the TFP slowdown intensified after the 1960s will continue until complete stagnation occurs near 2450. This effect is reinforced by the fact that the employment in $\mathrm{R} \& \mathrm{D}$ reaches the maximum in 2000 and decreases afterwards. As the model predicts, with increasing population and $\chi(A)$ higher than 1, stagnation may occur in finite time, which in fact occurs in this scenario.

It is also interesting to discuss what would happen in the future if the economy benefits from international knowledge (as in the exercises of Section 5.1.2). When $\chi(A)$ tends to 1.3529 , as in the last case, the economy may not stagnate due to international knowledge spillovers. After a period of decreasing economic growth that occurs roughly between 1980 (highly intensified after 2020) and 2480, the economy slowly recovers, but never returns to the 2000s growth rates as they reach near 30\% (generation growth rate corresponding to an annual average growth rate of $1.3 \%$ ) in the long-run, 21 percentage points below the 2000s level (corresponding to less 0.8 percentage points when the growth rate is to be taken annually). The rates at which the economy will grow in the very long run depend crucially on the growth rates of foreign knowledge (that may also tend to decrease according to $\left.\chi\left(A^{w}\right)\right) .{ }^{32}$

\footnotetext{
${ }^{32}$ Here, $w$ stands for the World. In this exercise we assumed that, after the 2000s, the annual growth rate
} 


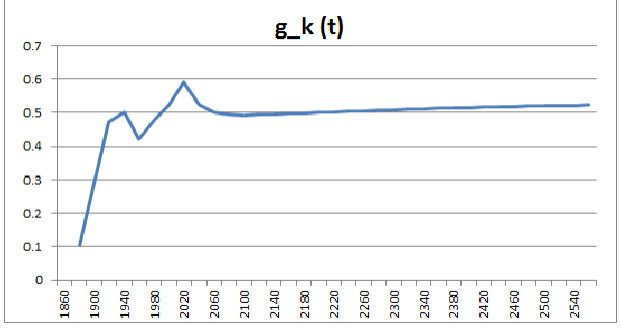

(a) Growth rate of Physical Capital per capita

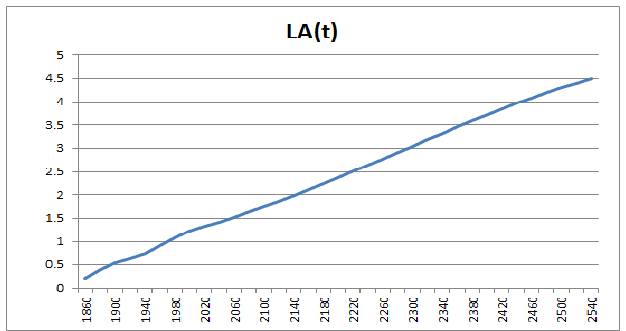

(c) Labor in R\&D Activities

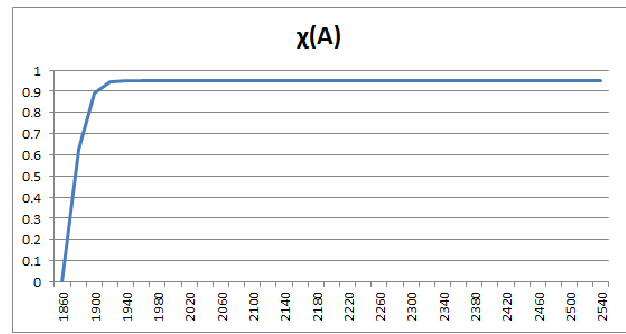

(e) Complexity Effect $\chi(A)$

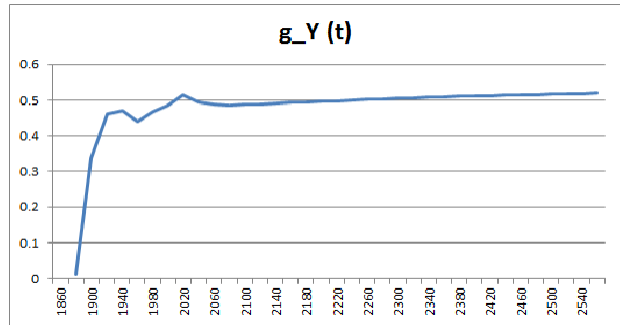

(b) Growth rate of Output per capita

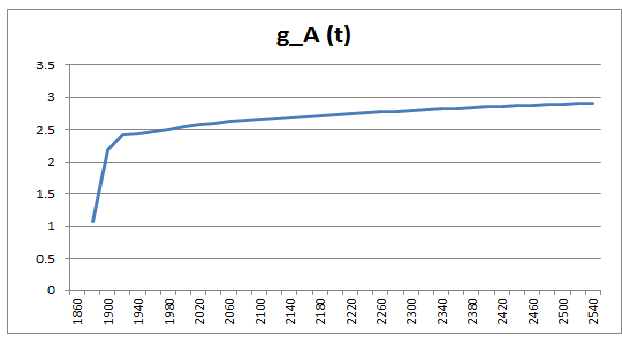

(d) Growth rate of Technological knowledge

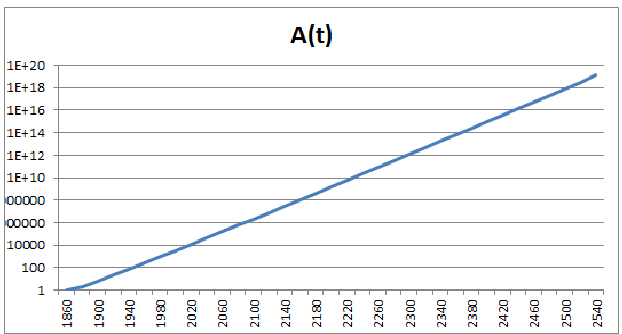

(f) Technological Knowledge ( $\log _{10}$ scale)

Figure 11: Evolution of the "model" series $\left(q=2.47\right.$ and $\left.b=1.4, k_{0}=0.025, L_{0}=0.75\right)$

With our third set of parameters under which the limit for the complexity effect is 1 $\left(\lim _{A \rightarrow+\infty} \chi(A)=1\right)$, the model closely estimates the "roaring twenties", the deceleration due to the World War II and the post-war acceleration, essentially due to the neoclassical mechanism (recall Figure 7), as also happened in the previous scenario. After growth of per capita output almost stagnates between 1980 and 2000, it presents very small differential annual growth rates between 2000 and 2020 (near 0.1 percentage points in the annual growth rate differences). In the following 200 years, output growth rates decrease by 0.39 percentage points annually, after which they stabilize. Figure 13 presents this scenario.

Finally, we describe the futuristic scenario corresponding to the case in which the complexity effect $\chi(A)$ tends to infinity (corresponding to the exercise depicted in Figure 8). ${ }^{33}$ The extension of this scenario to the future predicts that growth of physical capital will continue until the 1980s generation, although the productivity slowdown, beginning at the 1940s, intensifies after the 1960s and continues until 2120, year around which TFP growth will eventually go to zero. The output growth rate will decrease nearly 15 percentage points per generation (in an average of 0.7 percentage points per year) until 2120 , when it eventually oscillates around zero and would stagnate around 2800. In this scenario growth would stagnate due to increasing complexity even if population exhibited no growth. This means

of the world stock of patents decreases by 0.05 percentage points. Naturally, the highest this rate of decay, the less probable and intense will be the recovery of domestic growth rates.

${ }^{33}$ The corresponding figure is available upon request. 


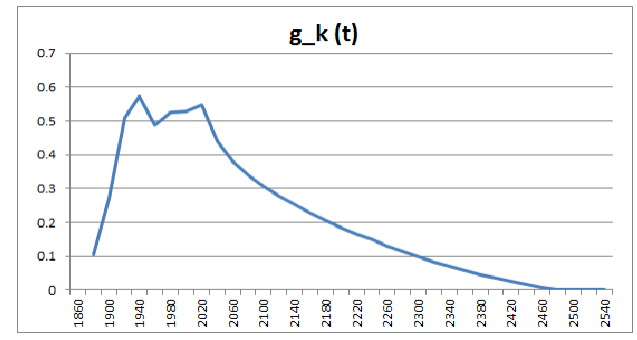

(a) Growth rate of Physical Capital per capita

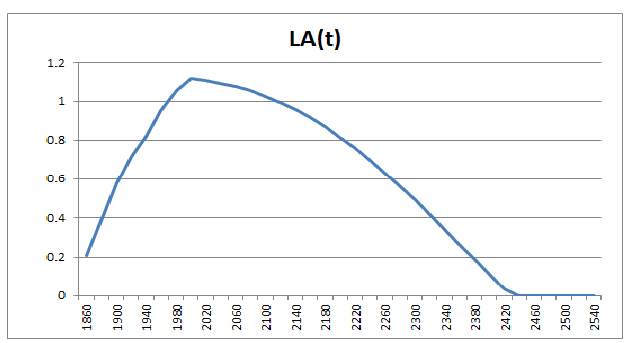

(c) Labor in R\&D Activities

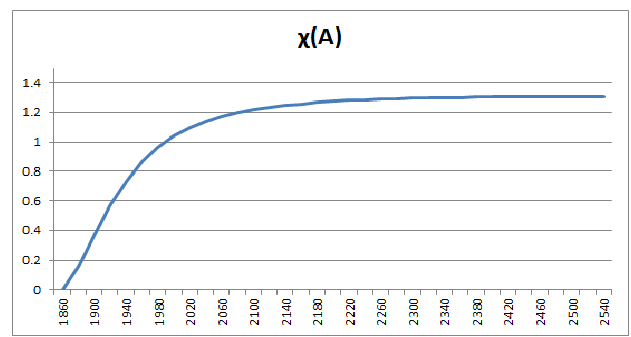

(e) Complexity Effect $\chi(A)$

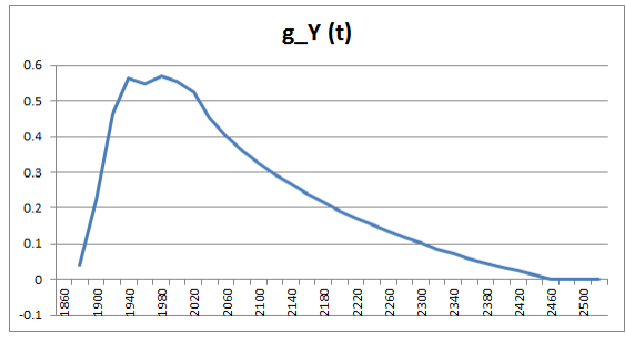

(b) Growth rate of Output per capita

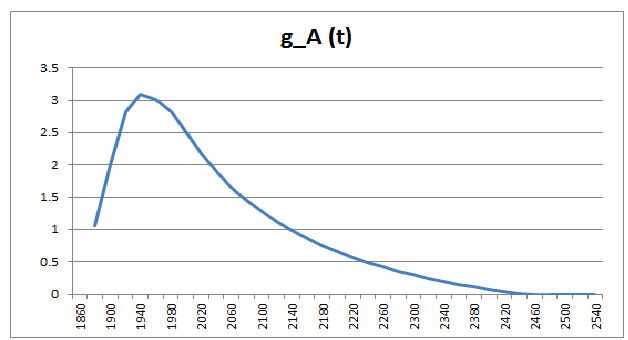

(d) Growth rate of Technological knowledge

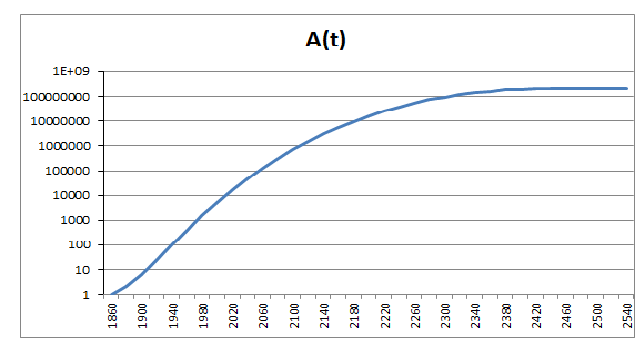

(f) Technological Knowledge ( $\log _{10}$ scale)

Figure 12: Evolution of the "model" series $\left(q=1.17\right.$ and $\left.b=0.23, k_{0}=0.025, L_{0}=0.75\right)$ 
that, in the long run, output per capita, physical capital and technological knowledge will stabilize at a given level.

Note that the scenarios in Figures 12 and 13 are the ones that best replicate the known economic history (recall Figures 6 and 7). In one of these scenarios, endogenous (positive) growth (with null scale effects) will eventually prevail - Figure 13 -, but in the other - Figure 12 -, in the long-run equilibrium, the economy will eventually stagnate in finite time as the increasing population induces an increase in complexity (although the population growth rate is, by that time, assumed to be quite small and converging to zero in the long-run, according to the demographic projections that back out our simulation) - recall Lemma 3 and the discussion in the end of Section 4.

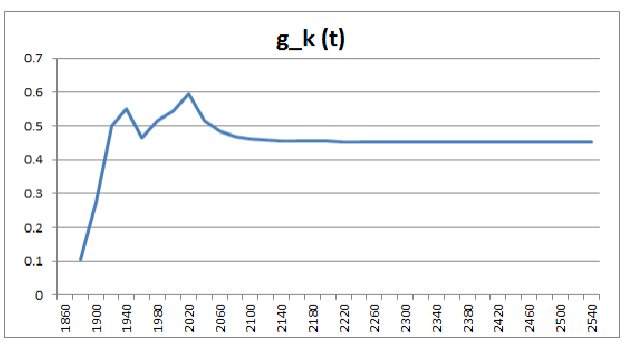

(a) Growth rate of Physical Capital per capita

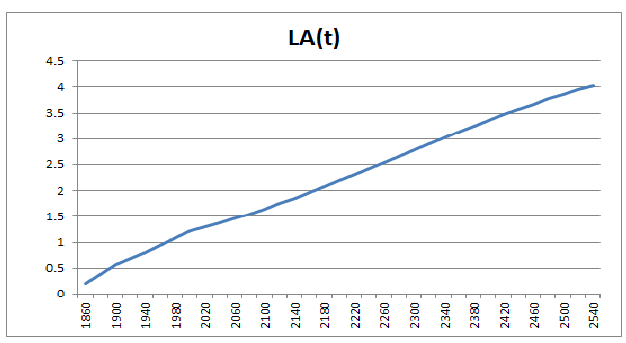

(c) Labor in R\&D Activities

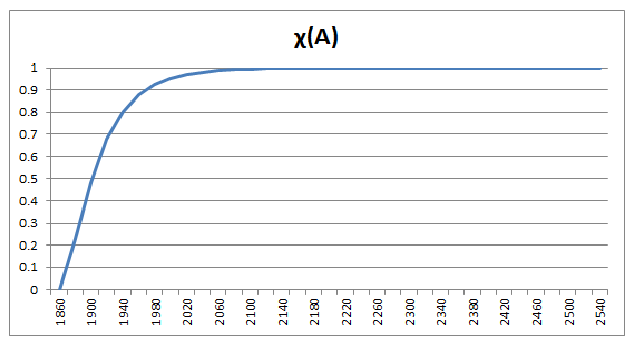

(e) Complexity Effect $\chi(A)$

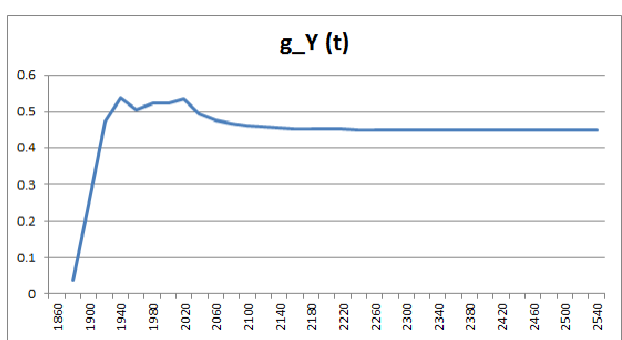

(b) Growth rate of Output per capita

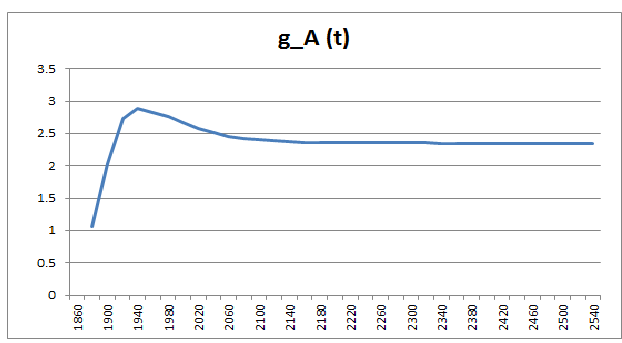

(d) Growth rate of Technological knowledge

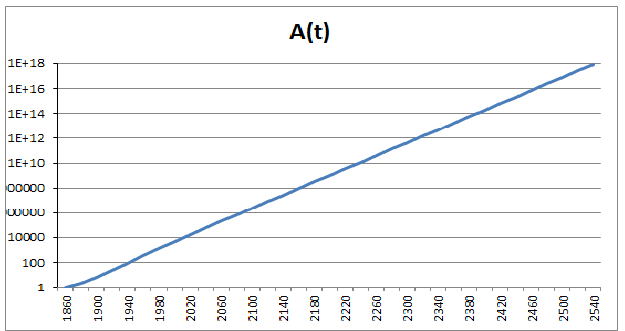

(f) Technological Knowledge ( $\log _{10}$ scale)

Figure 13: Evolution of the "model" series $\left(q=1.36\right.$ and $\left.b=0.36, k_{0}=0.025, L_{0}=0.75\right)$

\subsection{Discussion}

Overall these futuristic scenarios teach us that doing in-sample calibration such that the model replicates well the historical data, then, between 2000 and 2020, the world should experience a slowdown of growth rates which can be more or less pronounced depending on the parameterization of the complexity 'operator' based on entropy. Interestingly, in two out of the three combinations of estimated parameters for complexity, the economy will suffer significant (and long-lasting) slowdowns beginning on the eve of the XXI ${ }^{\text {th }}$ century. If the estimation-based scenario where the complexity index overpasses unity would verify, stagnation could occur within the first half of the millennium. Although the slowdown of the 
2000s (the great recession) has been attributed mainly to financial frictions and inefficiencies (which our stylized model does not incorporate), some authors began to question the sole financial roots of the crisis. For instance, in Kasparov et al. (2012), the authors point out that the collapse of advanced country growth is not merely a result of the financial crisis. They argue that these countries weakness reflects secular stagnation in technology and innovation. Fernald (2014) presents evidence according to which labor and total factor productivity (TFP) growth slowed prior to the great recession. He argues that it marked a retreat from the exceptional, but temporary, information technology-fueled pace from the mid- 1990s to early in the twenty- first century. Gordon (2012) also argues that the slowdown happening after the 2000's roots at the features of the innovations (computers, the web, mobile phones) of the late $\mathrm{XX}^{\text {th }}$ century, which spillovers were less long-lasting than the ones of the innovations of the second industrial revolution and anticipates scenarios of long anemic economic growth or even stagnation (see also Bloom et al, 2017). More recently, Brinca et al. (2016) pointed to the efficiency wedge (measured by $A$ in the final good production function) as the main source of the great recession at the end of the 2000 s decade. In our paper, we show this sort of effects arise as knowledge accumulation complexity effects related to the increasing market dimension - and, thus, with a permanent TFP slowdown or even stagnation in the long run being compatible with constant returns of the stock of knowledge in the generation of new ideas.

As a variation on the topic, Komlos (2014) argues that, bearing in mind Schumpeter's concept of creative destruction as the engine of development, and in comparison with the first and second industrial revolutions, the destructive (or obsolescence) component of innovations has recently increased relative to the size of the creative component, as the new technologies are often creating products which are close substitutes for the ones they replace. This conjecture could be accommodated, in the context of a growth model of expanding varieties and innovation clusters (e.g., Jones and Williams, 2000), by a time-varying statedependent rate of obsolescence induced by the introduction of new varieties (replacement by upgrades within an innovation cluster), with that rate increasing in the stock of varieties. Analytically, this mechanism would be isomorphic to the long-run effect of the complexity mechanism in our model. ${ }^{34}$

To sum up, by using entropy as a "first principle" operator of the complexity effect, which is flexible enough to account for null or some (positive or negative) scale effects in the long run, and an empirically validated calibration, our model is able to predict distinct future scenarios: (i) if the complexity index converges to a value below or equal to unity, there will be positive economic growth in the long run despite (eventual) population stagnation; (ii) if the complexity index converges to a value above unity, economic stagnation will occur due to population growth (although the latter will eventually stagnate in the long run).

\section{Conclusions}

We study the asymptotic properties of the knowledge production function as they are crucial to define endogenous growth. Our argument is based on a "first principles" approach to model an 'operator' for the complexity effect in the knowledge production function that ultimately eliminates scale effects. In fact, we take advantage of the proximity between the

\footnotetext{
${ }^{34}$ In particular, in this creative-destruction framework, index $\chi(A)$ could be regarded as proportional to the propensity of the economy to adopt new technologies (new varieties of goods) and, thereby, accelerate the destruction component of the innovation process. An index above unity might then correspond to the case where the destruction component dominates the creative one. In turn, parameter $q$ in function $\chi(A)$ might be regarded as the 'relative risk aversion' parameter that controls for the propensity to adopt, with a lower $q$ implying a higher $\chi(A)$ - see equation (3).
} 
entropy concept and the difficulty or complexity associated with the quantity of knowledge in Economics to build our 'operator' as a complexity index. This allows us to summarize the relevant economics pertaining to this issue with a minimum loss of information. The use of entropy as an 'operator' to define complexity in the endogenous growth literature provides an endogenous growth model with transitional dynamics in R\&D and with scale effects that diminish towards the steady state.

Using available data and different time spans, we were able to take this theoretical 'operator' to the data and estimate its parameters. Given the estimated parameters, we illustrate that the complexity 'operator' approaches well the data series for the complexity effect.

Additionally, the model can generate endogenous growth, with or without scale effects or stagnation. Scale effects decrease over time and may disappear or even become negative. Moreover, the state dependent time-varying complexity effect governed by entropy is essential to create transitional dynamics in TFP growth and an historically consistent evolution of the per capita output growth rates and levels. The model features a "stagnation" and a "growth" regimes and shifts may occur between them. Interestingly, population growth implies that the economy may shift from the "stagnation" to the "growth" regime, illustrating historical episodes of industrialization. However, the economy can also get trapped in a set of "stagnation" equilibria. Finally, with some parameterizations of the time-varying statedependent complexity effect, the economy may fall from the "growth" into the "stagnation" regime, which can happen even for a constant population.

We take the model to the data and show that the transitional dynamics it presents can match well the historical evolution of the developed world after the Industrial Revolution. Several parameter sets allow the model to replicate an almost ever increasing growth rate from the eve of the Industrial Revolution, with decelerations of growth during the World War II and accelerations during the "roaring twenties" or during the recovery from the war period during the 1960s. Finally, the model is also capable of predicting the productivity slowdown after the 1960 s.

Whatever the scenario in the future, the state-dependent time-varying complexity effect seems to contribute to the explanation of the growth slowdown that seems to characterize the current 2000-2020 generation, and can lead the economy to endogenous growth (with some or without scale effects) or to stagnation in the very long-run. The long-run outcome crucially depends on the asymptotic properties of the knowledge production function, and thus of the complexity effect governed by entropy.

Note that the model has policy implications regarding the effects of subsidization to R\&D. In particular R\&D subsidies can be a trigger to drive the economy from the "stagnation" to the "growth" regime and can also interact with the population dynamics and with complexity effects and influence the timing of possible future stagnation.

Overall, our model produces novel insights regarding the role of complexity in both the transitional and the long-run dynamics of the economy. First, our model generates a nonmonotonic U-inverted transition of the TFP growth rate commanded by the complexity index dynamics irrespective of the dynamics of the physical inputs. Second, the estimation of the complexity (entropy) index based on historical data suggests an eventual stabilisation of complexity as time goes by (which is shown to be related to the notion of entropy and of subextensive system). This speaks to the fact that, in practice, new ideas and new varieties of technological goods seem to have a heterogeneous impact on complexity, with some increasing it and others decreasing it. Finally, the model shows that it is not a necessary condition to have ever-increasing complexity as the stock of knowledge and of 
varieties of technological goods increase in order to generate permanent lower growth of TFP or even stagnation as a long-run equilibrium. Instead, the key feature is the level at which complexity stabilizes and thereby to what extent it curtails scale effects on growth.

\section{References}

Aghion, P., And P. Howitt (1992): "A Model of Growth Through Creative Destruction" Econometrica, 60(2), 323-351.

Alesina, A., E. Spolaore, and R. Wacziarg (2005): 'Trade, Growth and the Size of Countries" Handbook of Economic Growth, Volume 1B. (Editors: Philippe Aghion and Steven N. Durlauf), chapter 23.

Alvarez-Pelaez, M., and C. Groth (2005): 'Too little or too much R\&D?" European Economic Review, 49, 437-456.

Ang, J. B., And J. B. Madsen (2015): "What Drives Ideas Production Across the World?" Macroeconomic Dynamics, 19, 79-115.

Atkinson, A. B. (1970): "On the Measurement of Inequality" Journal of Economic Theory, $2(3), 244-263$.

Baier, S. L., G. Dwyer, and R. Tamura (2006): "How Important are Capital and Total Factor Productivity for Economic Growth?" Economic Inquiry, 44 (1), 23-49.

BenAssy, J. (1996): 'Taste for variety and optimum production patterns in monopolistic competition" Economics Letters, 52, 41-47.

(1998): "Is there always too little research in endogenous growth with expanding product variety?" European Economic Review, 42 (1), 61-69.

Bolt, J., And J. VAn Zanden (2014): 'The Maddison Project: collaborative research on historical national accounts," The Economic History Review, 67(3), 627-651. Data available at http://www.ggdc.net/maddison/maddison-project/orihome.htm (accessed in December, $26,2015)$.

Bloom, N., C. Jones, J. van Reenen and M. Webb (2017): Are Ideas Getting Harder to Find?, mimeo, version 0.8, July, available at https://web.stanford.edu/ chadj/IdeaPF.pdf (accessed in July 2017).

Bottazzi, L., And G. Peri (2007): "The international dynamics of R\&D and innovation in the long-run and in the short-run" The Economic Journal, 117, 586-511.

Brinca, P., V.V. Chari, P. Kehoe, and E. McGratten : "Accounting for Business Cycles" Handbook of Macroeconomics, second edn, ed. by Harald Uhlig and John Taylor, forthcoming, Amsterdam: Elsevier. https://www.elsevier.com/books/book-series/handbooks-ineconomics.

Bucci, A. (2015): "Product Proliferation, Population, and Economic Growth" Journal of Human Capital, 9(2), 170-197.

Bucci, A., L. Carbonari and G. Trovato (2017): Variety, Competition, and Population in Economic Growth: Theory and Empirics, Departmental Working Papers 2017-06, Department of Economics, Management and Quantitative Methods at Universit degli Studi di Milano.

Caruso, F., And C. Tsallis (2008): "Nonadditive entropy reconciles the area law in quantum systems with classical thermodynamics" Physical Review E, 78, 1-6. 
Ciccone, A., and K. Matsuyama (1996): "Start-up costs and pecuniary externalities as barriers to economic development" Journal of Development Economics, 49, 33-59.

Choi, I., AND P. SAIKkonen (2010): "Tests for nonlinear cointegration" Econometric Theory, 26, 682-709.

Coe, D., A. Hoffmaister and E. Helpman (2009): "International R\&D spillovers and institutions" European Economic Review, 53(7), 723-741.

Clark, G. (2009): "The Macroeconomic Aggregates for England, 1209-2008" Working Papers, University of California, Department of Economics, 09, 19. Available at http://hdl.handle.net/10419/58383 (accessed December 26, 2015).

Dalgaard, C-J., and C. Kreiner (2003): "Endogenous Growth: A Knife Edge or the Razor's Edge?" Scandinavian Journal of Economics, 105 (1), 76-86.

Dinopoulos, E., And P. Segerstrom (1999): "A Schumpeterian model of protection and relative wages" American Economic Review, 89(3), 450-472.

Dinopoulos, E., And P. Thompson (2000): "Endogenous Growth in a Cross-Section of Countries" Journal of International Economics, 51, 335-362.

Elsby, M., B. HobJin, and A. SAhin (2013): "The Decline of the U.S. Labor Share" Brookings Papers on Economic Activity, $19^{\text {th }}$ September.

Hidalgo, C. A. and Hausman, R. (2009): "The building blocks of economic complexity" Proceedings of the National Academy of Sciences, 106 (26): 10570-10575..

Feenstra, R. C., R. InklaAr, and P. Timmer (2015): "The Next Generation of the Penn World Table" American Economic Review, 105(10): 3150-82. Data available at www.ggdc.net/pwt (accessed in December 2015, 26).

Fernald, J. (2014): "Productivity and Potential Output before, during, and after the Great Recession" NBER Macroeconomics Annual 29, Cambridge, Massachusetts: National Bureau of Economic Research.

Galor, O., And O. MoAv (2002): "Natural Selection and the Origin of Economic Growth" Quartely Journal of Economics, 117, 1133-1191.

Galor, O., And D. WeIL (2000): "Population, Technology, and Growth: From the Malthusian Regime to the Demographic Transition and Beyond" American Economic Review, 90, $806-828$.

Gordon, R. (2012): Is U.S. economic growth over? Faltering innovation confronts the six headwings, NBER Working Paper 18315.

Groot, H., R. NAhuis (1998): "Taste for diversity and the optimality of economic growth" Economic Letters, 58, 291-295.

HA, J., And P. HowitT (2007): "Accounting for Trends in Productivity and R\&D: A Schumpeterian Critique of Semi-Endogenous Growth Theory" Journal of Money Credit and Banking, 39, 733-774.

Hall, R., J. Mairesse and P. Mohnen (2009): Measuring the Returns to RED, NBER Working Paper 15622 .

Iaria, A., C. Schwarz And F. Waldinger (2018): 'Frontier knowledge and scientific production: Evidence from the collapse of international science" Quarterly Journal of Economics, forthcoming.

Jones, C. (1995): "R\&D Based Models of Economic Growth" Journal of Political Economy, 103, 759-784. 
Jones, C. (2002): 'Sources of US Economic Growth in a World of Ideas" American Economic Review, 92(1), 220-239.

Jones, C., and J. Williams (2000): "Too Much of a Good Thing? The Economics of Investment in R\&D" Journal of Economic Growth, 5, 65-85.

Kaldor, N. (1961): "Capital Accumulation and Economic Growth" in F.A. Lutz and D.C. Hague, eds., The Theory of Capital, St.Martins Press, 1961, pp. 177-222.

Kasparov, G., and M. Levchin and P. Thiel (2012): The Blueprint: Reviving Innovation, Rediscovering Risk, and Rescuing the Free Market. W. W. Norton Company.

Komlos, J. (2014): Has Creative Destruction Become More Destructive? NBER Working Paper 20379.

Kremer, M. (1993): "Population and Growth: One Million BC to 1990" Quarterly Journal of Economics, 108, 681-716.

Lin, J.-L. and C. Granger (2004): "Testing nonlinear cointegration" COMPSTAT 2004 Proceedings in Computational Statistics, ed. Jaromir Antoch, Springer-Verlag, 1413-1419.

LuCAS, R. (1988): "On the Mechanics of Economic Development" Journal of Monetary Economics, 22, 3-42.

Magalhães, M. and O. Afonso (2017): "A multi-sector growth model with technology diffusion and networks" Research Policy, 46, 1340-1359.

Maddison (2007): Contours of the World Economy 1-2030 AD. Oxford University Press. Data available in http://www.ggdc.net/MADDISON/oriindex.htm, (accessed in December, 26, 2015).

Marco, A. C., M. Carley, S. Jackson , and A. Myers (2015): "The USPTO Historical Patent Data Files," U.S. Patent and Trademark Office Working Paper, 2015-1. Available at http://www.uspto.gov/economics. Data available at. http://www.uspto.gov/learningand-resources/electronic-data-products/historical-patent-data-files. (Accessed January 15, 2016).

Mokyr, J. (2005): "Long-term Economic Growth and the history of technology" Handbook of Economic Growth, Volume 1B: chapter 17. Elsevier, Editors: Philippe Aghion and Steven N. Durlauf.

Patil, G. P., and C. Taillie (1982): "Diversity as a Concept and its Measurement" Journal of the American Statistical Association, 77(379), 548-561.

PARK, J. Y., and P. Phillips (2001): "Nonlinear regressions with integrated time series" Econometrica, 69, 117-161.

Peretto, P. And J. Smulders (2002): "Technological distance, growth and scale effects" Economic Journal, 112 (481), 603-624.

(2015): "From Smith to Schumpeter: A Theory of Take-Off and Convergence to Sustained Growth" European Economic Review, 78, 1-26.

Romer, P. M. (1990): "Endogenous Technological Change" Journal of Political Economy, 98(5), 71-102.

Segerstrom, P. (1998): "Endogenous Growth Without Scale Effects" American Economic Review, 88 (5), 1290-1310.

Shannon, C. E. (1948): "A Mathematical Theory of Communication" Bell System Technical Journal, 27, 379-423 \& 623-656. 
Sokoloff, K. (1988): "Inventive Activity in Early Industrial America: Evidence From Patent Records, 1790-1846" Journal of Economic History, 48(4), 813-850 .

Strulik, H. (2014): 'Knowledge and Growth in the Very Long Run" International Economic Review, 55(2), 459-482 .

Strulik, H., K. Prettner , and A. Prskawetz (2013): "The past and future of knowledge-based growth" Journal of Economic Growth, 18, 411-437.

Tsallis, C. (1988): "Possible Generalization of Boltzmann-Gibbs Statistics" Journal of Statistical Physics, 52(1/2), 479-487.

Tsekouras, G. and C. Tsallis (2005): 'Generalized entropy arising from a distribution of q indices" Physical Review E, 71, 1-8.

Ugur, M., E. Trushinb, E. Solomona, and Francesco Guidi (2016): "R\&D and productivity in OECD firms and industries: A hierarchical meta-regression analysis" Research Policy, 45, 2069-2086. 


\section{APPENDIX}

\section{A Model with international knowledge diffusion}

Using (18), (20) and the associated free-entry condition $w_{t} \frac{L_{t}^{\chi\left(A_{t}\right)}}{\delta A_{t}^{\phi}\left(A_{t}^{w}\right)^{\mu}}=\pi_{t}$, and following the steps as in Section 4 (using again equation (17)), we first obtain the share of labor allocated to $\mathrm{R} \& \mathrm{D}$ and the final good production as:

$$
l_{t}^{Y}=\min \left\{1, \frac{1}{\alpha \delta} \frac{1}{L_{t}^{1-\chi}} \frac{A_{t}^{1-\phi}}{\left(A_{t}^{w}\right)^{\mu}}\right\} \quad ; l_{t}^{A}=\max \left\{0,1-\frac{1}{\alpha \delta} \frac{1}{L_{t}^{1-\chi}} \frac{A_{t}^{1-\phi}}{\left(A_{t}^{w}\right)^{\mu}}\right\}
$$

Inserting (14) into (16), then replacing $w_{t}$ with expression (17) and finally using (21) and (18), we obtain the difference equation for physical capital as follows:

$$
\Delta k_{t}=\bar{a} \frac{\left(A_{t}\right)^{\sigma-\alpha(1-\phi)}\left(A_{t}^{w}\right)^{\alpha \mu} L_{t}^{\alpha\left(1-\chi\left(A_{t}\right)\right)} k_{t}^{\alpha}}{1+n}-k_{t}
$$

where $\bar{a}=\frac{\beta(\alpha \delta)^{\alpha}(1-\alpha)}{1+\beta}$.

\section{B Higher returns to knowledge}

In this Appendix, we also test the differences of the results to the consideration of an alternative higher value of $\sigma=0.64$, a value also considered in Jones and Williams (2000). Figure 14 shows the adjustment between empirical series for $\chi$ and (GMM) estimated theoretical series for $\chi(A)$ for this higher value for the returns to knowledge.

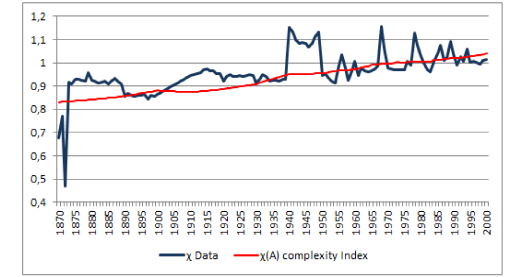

(a) Data TFP index 1870-2000, $\sigma=0.64, q=1.24$ and $b=0.31$

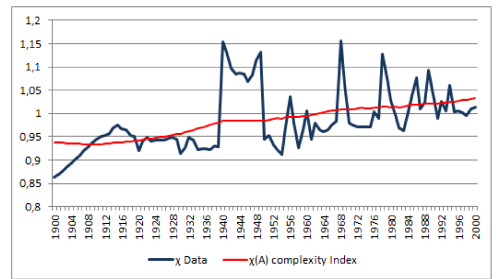

(b) Data TFP index 1900-2000, $\sigma=0.64, q=1.31$ and $b=0.36$

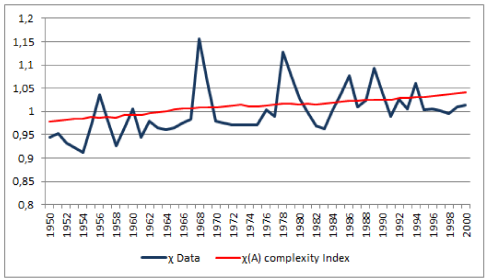

(c) Data TFP index 1950-2000, $\sigma=0.64, q=1.16$ and $b=0.25$

Figure 14: Comparison between empirical series for $\chi$ (blue series) and (GMM) estimated theoretical series for $\chi(A)$ (red series). Values for $q$ and $b$ are estimated as done in Section 3.

In Figure 15 there is a slowdown in TFP growth rate in the late $\mathrm{XX}^{\text {th }}$ century (although its growth is higher than the one the data series show). Overall, the model TFP growth, GDP per capita growth and GDP per capita levels overpredict the data series in most of the period. This is consistent with the fact that this value of the returns of specialization is quite high when compared to the average of the available empirical estimates (see e.g. Hall et al., 2009 for a review). 


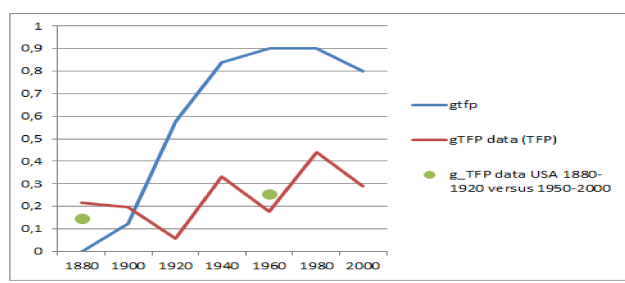

(a) TFP growth; gTFP data is averaged from the United States (own data) and from the United Kingdom - Clark (2009); g_TFP data USA 18801920 versus 1950-2000 are averages of the United States TFP growth rates over long 50 years periods avoiding the Great Depression and World Wars.

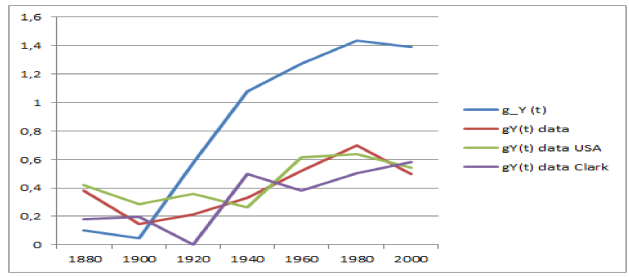

(c) GDP per capita growth rates; $g Y(t)$ data is for average of countries (see text) and $g Y(t)$ data $U S A$ is from Maddison Project and $g Y(t)$ data Clark is data for the United Kingdom from Clark (2009).

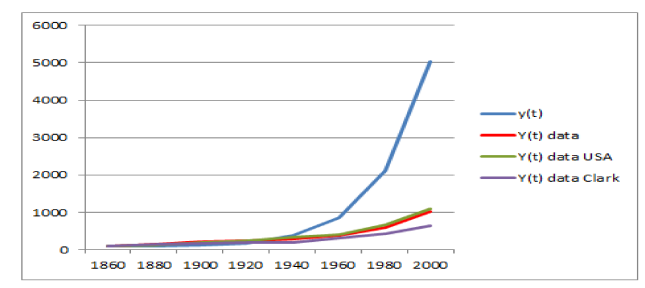

(b) GDP per capita levels; $Y(t)$ data is average of countries (see in the text) and $Y(t)$ data USA are from Maddison Project and $Y(t)$ data Clark is data for the United Kingdom from Clark (2009).

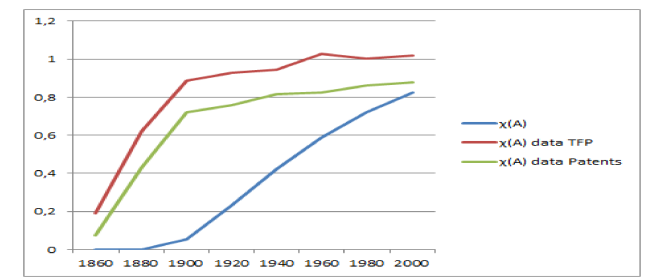

(d) Complexity Effect $\chi(A) ; \chi(A)$ data TFP and $\chi(A)$ data Patents are respectively from TFP data and Patents data as calculated in Section 3.

Figure 15: Evolution of the main "model" series (blue line series) and comparison with "data" series $\left(\sigma=0.64, q=1.24\right.$ and $\left.b=0.31, k_{0}=0.025, L_{0}=0.75, A_{0}=1\right)$. 
CeBer Working Papers

(Available on-line at www.uc.pt/go/ceber)

2018-05 Endogenous Growth and Entropy - Tiago Neves Sequeira, Pedro Mazeda Gil \& Óscar Afonso

2018-04 Determinants of overall and sectoral entrepreneurship: evidence from Portugal Gonçalo Brás \& Elias Soukiazis

2018-03 Young and healthy but reluctant to donate blood: An empirical study on attitudes and motivations of university students - Tiago Henriques \& Carlota Quintal

2018-02 The Iberian electricity market: Price dynamics and risk premium in an illiquid market Márcio Ferreira \& Hélder Sebastião

2018-01 Health Investment and Long run Macroeconomic Performance: a quantile regression approach - Francisca Silva, Marta Simões \& João Sousa Andrade

2017-12 Deflation in the Euro Zone: Overview and Empirical Analysis - Pedro Bação \& António Portugal Duarte

2017-11 Fiscal Consolidation Programs and Income Inequality - Pedro Brinca, Miguel H. Ferreira, Francesco Franco, Hans A. Holter \& Laurence Malafry

2017-10 The interconnections between Renewable Energy, Economic Development and Environmental Pollution. A simultaneous equation system approach - Elias Soukiazis, Sara Proença \& Pedro André Cerqueira

2017-09 The Renminbi: A Warrior for Competitiveness? - Pedro Bação, António Portugal Duarte \& Matheus Santos

2017-08 Le Portugal et l'Euro - João Sousa Andrade

2017-07 The Effect of Public Debt on Growth in Multiple Regimes in the Presence of Long-Memory and Non-Stationary Debt Series - Irina Syssoyeva-Masson \& João Sousa Andrade

2017-06 The Blank and the Null: An examination of non-conventional voting choices - Rodrigo Martins

2017-05 Where is the information on USD/Bitcoins hourly price movements? - Helder Sebastião, António Portugal Duarte \& Gabriel Guerreiro

2017-04 The response of non-price competitiveness and productivity due to changes in passed income gaps. Evidence from the OECD countries - Pedro André Cerqueira, Micaela Antunes \& Elias Soukiazis 
2017-03 Dutch Disease in Central and Eastern European Countries - João Sousa Andrade \& António Portugal Duarte

2017-02 On the gains of using high frequency data and higher moments in Portfolio Selection- Rui Pedro Brito, Hélder Sebastião \& Pedro Godinho

2017-01 Growth adjustments through non-price competitiveness and productivity. A cumulative causation approach- Elias Soukiazis, Micaela Antunes \& Pedro André Cerqueira

A série CeBER Working Papers foi iniciada em 2017. 